\title{
Variation in the life history strategy of cells underlies tumor's functional diversity
}

Tao Li ${ }^{1,2,3,4}$, Jialin Liu ${ }^{2,4}$, Jing Feng ${ }^{1,2,3,4}$, Zhenzhen Liu ${ }^{2,4}$, Sixue Liu ${ }^{2,4}$, Minjie Zhang ${ }^{2,4}$, Yuezheng Zhang ${ }^{2,4}$, Yali $\mathrm{Hou}^{2,4}$, Dafei $\mathrm{Wu}^{2,4}$, Chunyan $\mathrm{Li}^{2,4}$, Young-Bin Chen ${ }^{5}$, Chung-I Wu ${ }^{2,6,7}$, Hua Chen ${ }^{2,4} \&$ Xuemei Lu ${ }^{1,2,3,4, *}$

${ }^{1}$ State Key Laboratory of Genetic Resources and Evolution, Kunming Institute of Zoology, Chinese Academy of Science, Kunming 650223, China.

${ }^{2}$ CAS Key Laboratory of Genomic and Precision Medicine, Beijing Institute of Genomics, Chinese Academy of Sciences, Beijing 100101, China.

${ }^{3}$ Center for Excellence in Animal Evolution and Genetics, Chinese Academy of Sciences, Kunming 650223, China.

${ }^{4}$ University of Chinese Academy of Sciences, Beijing 100049, China.

${ }^{5}$ Key Laboratory of Animal Models and Human Disease Mechanisms of the Chinese Academy of Sciences and Yunnan Province, Kunming Institute of Zoology, Kunming 650223, China.

${ }^{6}$ State Key Laboratory of Biocontrol, College of Ecology and Evolution, Sun Yat-Sen University, Guangzhou 510275, China. ${ }^{7}$ Department of Ecology and Evolution, University of Chicago, Chicago, IL 60637, USA.

*e-mail: xuemeilu@mail.kiz.ac.cn.

\section{Abstract}

Classical $r$ - vs. $K$-selection theory describes the trade-offs between high reproductive output and competitiveness and guides research in evolutionary ecology ${ }^{1-5}$. While its impact has waned in the recent past, cancer evolution may rekindle it ${ }^{6-10}$. Indeed, solid tumors are an ideal theater for $r$ - and $K$-selection and, hence, a good testing ground for ideas on life-history strategy evolution $^{11,12}$. In this study, we impose $r$ - or $K$-selection on HeLa cells to obtain strongly proliferative $\mathrm{r}$ cells and highly competitive K cells. RNA-seq analysis indicates that phenotypic trade-offs in $\mathrm{r}$ and $\mathrm{K}$ cells are associated with distinct patterns of expression of genes involved in the cell cycle, adhesion, apoptosis, and contact inhibition. Both empirical observations and simulations based on an ecological competition model show that the trade-off between cell proliferation and competitiveness can evolve adaptively and rapidly in naïve cell lines. It is conceivable that the contrasting selective pressure may operate in a realistic ecological setting of actual tumors. When the $\mathrm{r}$ and $\mathrm{K}$ cells are mixed in vitro, they exhibit strikingly different spatial and temporal distributions in the resultant cultures. Thanks to this niche separation, the fitness of the entire tumor increases. Our analyses of life-history trade-offs are pertinent to evolutionary ecology as well as cancer biology. 


\section{Introduction}

2 Diverse environmental conditions act on populations and species, leading to selection-driven

3 emergence of niche-specific adaptive phenotypes and preventing the emergence of a 4 "superorganism"13. Such a superorganism, often dubbed "Darwinian demon," would produce very large numbers of offspring and live indefinitely ${ }^{14}$. Existence of such entities is contrary to life history theory and empirical observation. Indeed, evolution of adaptive traits is typically restricted by fitness constrains ${ }^{15}$. These constrains often take the form of trade-offs whereby a life history trait can affect different components of fitness in opposite directions. Thus, directional evolution of such a trait would increase some measures of organismal performance at the expense of others ${ }^{16}$. The trade-offs are fundamentally shaped by the way the organism allocates its energy and resources between reproduction and survival ${ }^{17,18}$. Due to the complexity of life-history traits and environmental variables, empirical measurement of plausible trade-offs and their driving forces remains difficult ${ }^{15}$.

In contrast to natural organisms, cancers appear to be exempt from all constraints during the process of somatic cell evolution. A series of biological features, the so-called "hallmarks of cancer", are characterized by fast proliferation, resistance to low oxygen and crowded environment, and the ability to recruit blood vessels and escape the immune system ${ }^{19}$. How can all aspects of fitness be maximized in cancers? Perhaps heterogeneity within tumors enables several cell lineages to adopt a variety of characteristics and colonize different niches in a changing environment ${ }^{12,20-25}$. The internal and external microenvironments that cancer cells are confronted with in a multicellular organism are akin to complex ecosystems ${ }^{25-34}$. Trade-offs between cell proliferation and survival may apply to such cancer cell populations ${ }^{25,33,35}$. Both rapid cell proliferation and stable survival strategies must complement each other to achieve high fitness of a tumor as a whole ${ }^{12}$. Therefore, cancer cell populations can be used to test selection pressures and adaptive strategies that govern the trade-off between increasing proliferation and survival, and the ecological mechanisms that underlie these tradeoffs in heterogenous populations.

An important and well-defined environmental variable governing evolutionary change is population density relative to essential resources ${ }^{36}$. The theory of density-dependent natural selection, often called $r$ - and $K$-selection, states that at extreme population densities evolution produces alternative strategies ${ }^{37}$. The trade-offs are presumed to arise because the genotypes with the highest fitness at high population densities have low fitness at low density and vice- 
versa $^{15,38}$. The r-populations are selected for high intrinsic rate of growth $(r)$ in environments where population density is low and resources are abundant but perform badly at high density. In contrast, K-populations, experiencing strong competition for limited resources under high density conditions, should evolve high intraspecific competitive ability and enhance their carrying capacity $(\mathrm{K})$. K-selected populations do not have high growth rates because they are near the carrying capacity for their environment ${ }^{1,2,5,39,40}$.

In this study, we performed artificial selection for cell density on HeLa cell lines in order to amplify the diversity of cell growth within tumors. We asked whether selection under different density regimes modifies per capita growth rates and competitiveness as predicted by models that postulate a trade-off between $r$ - and $K$-selection. To examine the phenotypic trade-offs at the molecular level, we carry out RNA-seq and explore the specific gene expression and pathway characteristics of $r$ and $\mathrm{K}$ cells. The dynamics of density-dependent population growth in mixed populations change with the proportions of $\mathrm{r}$ and $\mathrm{K}$ cells within them. We model these dynamics and fit our models to empirical observations in order to quantify the interaction among the various trade-off phenotypes in a heterogenous population and their effect on fitness of whole tumors.

\section{Results}

Density-dependent selection and fitness changes of $\mathrm{r}$ - and K-selected cell

The initial cell population (IN cells) was a single cell clone from a HeLa cell line. When the size of the population reached $10^{7}$ cells, we divided the clone in two sub-populations. One subpopulation was marked with eGFP (IN_G) and the other with dsRed (IN_R) through lentivirus transfection. Three $r$-selection replicates (using IN_G cells) and three $K$-selection replicates (using IN_R cells) were derived independently. After approximately 200 passages under $r$ selection (the low-density condition) and about 130 passages under $K$-selection (the highdensity condition), we obtained six populations of $r$-selected ( $\mathrm{r}$ cells) and six of K-selected cells ( $\mathrm{K}$ cells). The density-dependent selection scheme is illustrated in Figure 1a. 
To test whether the selected $\mathrm{r}$ and $\mathrm{K}$ cells are more adapted to their corresponding conditions than the ancestral IN cells, we pairwise co-cultured the three types of cells at high and low density. $r$ cells become dominant within two passages (three days, Extended Data Figure 1a) in the r-IN mix, suggesting that the $r$ cells have evolved higher fitness than IN cells under these conditions. Likewise, K cells rapidly take over the K-IN mixed population (in four days, two passages, Extended Data Figure 1b). Both $\mathrm{r}$ and $\mathrm{K}$ cells display better fitness than their counterpart in the $\mathrm{r}-\mathrm{K}$ mix under corresponding selection conditions (Figure $1 \mathrm{~b}$ and $1 \mathrm{c}$ ). We thus successfully selected for alternative life histories in our experiment. growth environments

To explore the possibility that the $\mathrm{r}$ and $\mathrm{K}$ cells exhibit a trade-off in their density-dependent population growth, we first measured the growth rates of these cells in $2 \mathrm{D}$ in vitro systems at low and high density. Under low-density, $r$ cells grow faster than K cells (Figure 1d). When the test was performed at high density, there is no significant difference between $\mathrm{r}$ and $\mathrm{K}$ cells, whereas growth rates of r-cell populations decrease remarkably compared to low density conditions (Figure 1d).

We next tested the difference between $\mathrm{r}$ and $\mathrm{K}$ cells in their density-dependent rates of population growth in 3D cellular environments. We quantified tumorigenicity by measuring colony growth and formation in a semi-solid agarose gel. $\mathrm{r}$ cells displayed a significantly higher rate of colony formation than $\mathrm{K}$ cells within seven days (Figure 1e). However, K-cell clones were significantly larger than r-cell colonies on day 21 (Figure 1f). The diameter of K-cell clones was $5 \mathrm{~mm}$ on average, while it was $0.5 \mathrm{~mm}$ for $\mathrm{r}$-clones. This suggests $\mathrm{K}$-cells have evolved to tolerate high density better than r-cells.

Xenograft mouse models were used to investigate the population growth rate of $\mathrm{r}$ and $\mathrm{K}$ cells in vivo. Cells were injected into the inguinal skin of BALB/c Nude mice. Tumor nodules were established in all xenografts in about two weeks. The mean growth rate of r-cell tumors was significantly higher than that of K-cell tumors in vivo (Figure 1g). 
89

The net rate of population growth is determined by both cell death and birth rates. Using annexin-V and DAPI staining, reflecting cell death and the G0/G1 phase of the cell cycle, we measured the proportions of dead cells and distinguished the resting/quiescent (G0/G1) from total cells in the $\mathrm{r}$ and $\mathrm{K}$ populations at high and low density. Figure 2a shows that the proportion of G0/G1 phase cells is lower in the $\mathrm{r}$ - than in the $\mathrm{K}$-cell populations, indicating that $\mathrm{r}$ cells proliferate relatively quickly at both low and high density. It also demonstrates that $\mathrm{K}$ cell birth rate does not increase at high density.

The $K$ cell death rate is relatively stable under both conditions (Figure $2 b$ ). In contrast, the $r$ cell death rate increases significantly under high compared to low density. The $r$ cells also die more frequently at high density than $K$ cells (Figure $2 b$ ). The high birth and death rates of $r$ cells suggest that they have evolved to quickly produce offspring rather than to increase their survival, while $K$ cells tend to ensure offspring quality rather than number. The high incidence of cell death leads to a decrease in growth rate of $r$ cells at high density, and the effect of density in $r$-selected populations is mainly on cell death.

Transcriptome characteristics support a trade-off between cell proliferation and survival in r- and K-cells

To find molecular characteristics that may be correlated with the phenotypic trade-offs in $\mathrm{r}$ and $\mathrm{K}$ cells, we carried out RNA-seq in 22 samples, including two replicates of initial cell populations, five $\mathrm{K}$ cell lines, five $\mathrm{r}$-cell lines under routine cell culture conditions, and $\mathrm{r}$ - and K- replicate lines under high density stress. Multiple comparisons were performed among transcriptional profiles of cell lines across and within density conditions. Differentially expressed genes in these comparisons were identified using standard methods ${ }^{41,42}$. Figure $2 \mathrm{c}$ shows that $r$ and IN cell populations cluster closely and differ from the K-cell populations under routine cell-culture conditions (at low density). We detect that 3161 genes show significant difference in gene expression (DEGs) between the $\mathrm{r}$ and K cells (with 1748 up- and 1413 downregulated genes in $\mathrm{K}$ cells, Extended Data Table 1). Using the Functional Annotation Tool from the DAVID package, we found 25 pathways significantly enriched for these differentially expressed genes. The top three of these are the spliceosome, pathways involved in cancer, and ribosome biogenesis (Extended Data Table 2). 
Genes from the same signaling pathway may increase or decrease its overall expression level, resulting in the enhancement or inhibition of related biological functions ${ }^{43-45}$. The top 20 highly expressed pathways in K or $r$ cells based on the GAGE (General Applicable Gene-set

121 Enrichment for Pathway Analysis) ${ }^{46}$ are listed in Figure $2 \mathrm{~d}$. The upregulated pathways in $\mathrm{K}$ 122 cells include cell and focal adhesion, ErbB signaling, ECM-receptor interaction, phagosome, 123 regulation of actin cytoskeleton, and Jak-STAT signaling. The cell cycle (upper panel in Figure $1242 \mathrm{~d}$ ), metabolism, and genetic information processing (such as ribosome biogenesis and mRNA surveillance) pathways are significantly highly expressed in $\mathrm{r}$ cells (Figure $2 \mathrm{~d}$ ).

We next detected the transcriptional difference in responding to density constraints between $\mathrm{r}$ and $\mathrm{K}$ cells. Dramatic change at the transcriptional level is found in $\mathrm{r}$ cells when they are grown at high density. The expression levels of 6373 genes are significantly different from low density (Extended Data Table 1), while the number of DEGs is 2278 in K cells (Extended Data Table 1). Compared to the gene expression profiles under low-density conditions, 1775 genes (859 genes up-regulated; 916 genes down-regulated) present the same trend of expression change in both $\mathrm{r}$ and $\mathrm{K}$ cells under high density. These are involved in metabolic and serial RNA related pathways. These results suggest that high culture density has a prominent effect on cell metabolism (Extended Data Table 3). In addition to these common changes, only 503 $(=2278-1775)$ genes respond to density change specifically in K cells. The number of genes (6373-1775=4598 genes) responding to the density change in $r$ cells is approximately nine times larger than that, indicating that $r$ cells are more sensitive and less stable at high density than K cells.

\section{Underrepresentation of contact inhibition in $\mathrm{K}$ cells}

The direct cellular response to cell density is contact inhibition which mediates cell growth and proliferation via interplay between growth signaling pathways and density constraints. Contact inhibition of proliferation is typically absent in cancer cells ${ }^{47}$. Both RNA-seq analysis and trypsinization assay showed that $\mathrm{K}$ cells are prone to form cell-cell adhesion at high density

144 (Figure 2d and Extended Data Figure 6), implying a loss or decrease of contact inhibition ${ }^{48}$. In contrast, cell cycle arrest and the slower growth may still be triggered in $\mathrm{r}$ cells by signaling pathways that downregulate proliferation in a cell-density dependent manner ${ }^{49}$. One such pathway is the Hippo-YAP signaling pathway, which is largely responsible for inhibiting cell 
that expression of YAP/TAZ is significantly upregulated in K cells, while the hippo-signaling pathway is overrepresented in gene expression comparison between $r$ and $\mathrm{K}$ cells (Extended Data Table 2). In addition, the crosstalk among the hippo signaling and eight other pathways (including adherens junction, focal adhesion, tight junction, PI3K-Akt signaling, mTOR signaling, ErbB signaling, TGF-beta signaling, and Wnt signaling) constructs a regulation network associated with cell cycle, cell survival, cell proliferation, and apoptosis ${ }^{51-53}$. A gene cluster analysis shows that the $\mathrm{r}$ and $\mathrm{K}$ cells can be distinguished by the expression profile of DEGs involved in these nine signaling pathways (Extended Data Figure 2).

The expression of anti-apoptotic factors can be activated by the transport of dephosphorylated YAP into the cell nucleus ${ }^{52}$. In reacting to high cell density, activated LATS1/2 regulates phosphorylation of the coactivator YAP/TAZ, promoting cytoplasmic localization of YAP and leading to cell apoptosis and restriction of organ overgrowth ${ }^{54}$. Overexpression or hyperactivation of YAP/TAZ has been observed in many types of tumors, stimulating growth and proliferation ${ }^{55-57}$. We performed an immunofluorescence assay to identify the localization of YAP/TAZ in $\mathrm{r}$ and $\mathrm{K}$ cells under both low- and high-density conditions. The localization of YAP/TAZ in the cytoplasm and nuclei was observed in both $r$ and $\mathrm{K}$ cells at low density (Extended Data Figure 3a). In contrast, the nuclear localization of $\mathrm{YAP} / \mathrm{TAZ}$ is absent in $\mathrm{r}$ cells but is still maintained in $\mathrm{K}$ cells grown at high density (Figure 3a). This suggests that YAP/TAZ phosphorylation is inhibited in $\mathrm{K}$ cells under high density, resulting in the loss of cell contact inhibition ${ }^{58}$. Consequently, cell apoptosis may be triggered by cytoplasmic localization of YAP in $\mathrm{r}$ cells but not in K cells as cell density increases.

In addition, Dlg-2 is a cell polarity gene in the hippo signaling pathway, regulating the inhibition of phosphorylated active YAP/TAZ proteins in the cytoplasm ${ }^{51,59}$. Our transcriptome analysis shows that expression of Dlg-2 is significantly higher in K cells at high than at low density (Extended Data document 1). We confirmed this by RT-PCR (Extended Data Figure 3b). We carried out an siRNA assay to knock down the expression of Dlg-2 in $\mathrm{K}$ cells (Extended Data Figure 3c). The apoptosis rate of Dlg-2 knock-down K cells significantly increased at high density (Figure 3b), confirming that the high expression level of Dlg-2 contributes to survival of $\mathrm{K}$ cells grown under these conditions. 

K cells

\section{1) Empirical observations}

181 Population proportion changes, as well birth and death rates of $\mathrm{r}$ and $\mathrm{K}$ cells were measured in 182 a co-culture assay. When $\mathrm{r}$ and $\mathrm{K}$ cells are co-cultured at high density, the proportion of $\mathrm{r}$ cells 183 decreases over time (Figure 1c, Extended Data Figure 3) and the death incidence of $r$ cells is 184 significantly higher than of $\mathrm{K}$ cells (Figure 4a). The death rate and G0/G1 phase proportion among $\mathrm{r}$ cells in co-cultures are both significantly higher than when the $\mathrm{r}$ cells are cultured individually under crowded conditions (Figure $4 \mathrm{a}$ and $4 \mathrm{~b}$ ). Compared to r, K cells have a relatively stable incidence of death and proportion of cells in G0/G1 phase under co-culture or in individual cultures, although their death rate increases under co-culture (Figure $4 \mathrm{a}$ and $4 \mathrm{~b}$ ). These results show that the birth of $r$ cells is restrained and cell death is accelerated when these two different types of cells are cultured together at high density, suggesting that they are in competition when they coexist.

Competition may result in niche separation among co-existing populations in an ecological community $^{60}$. To examine this possibility, we carried out co-cultures where approximately $10^{6}$ $\mathrm{r}$ and $\mathrm{K}$ cells were well mixed at equal proportion and seeded in the centers of wells in six-well plates. Three replicate co-cultures were scanned every 72 hours. We observed that $r$ and $\mathrm{K}$ cells in the co-culture assay tended to occupy different regions in a well. The $\mathrm{r}$ cells disperse to the

197 periphery, while K cells grow and occupy the crowded central area (Figure 4c). This 198 observation reveals an additional density-dependent difference in the phenotypes of $\mathrm{r}$ and $\mathrm{K}$ 199 cells $^{61,62}$.

\section{2) Simulation and parameter estimation}

201 To investigate the inter-population relationship between $\mathrm{r}$ and $\mathrm{K}$ cells, we adopt the Lotka-

202 Volterra model which has been widely used to study population interaction ${ }^{63,64-54}$. Mixed populations were initiated in our computer simulations with different fractions of $\mathrm{r}$ and $\mathrm{K}$ cells (Materials and Methods), followed by 30 cell passages at high density. We compared the growth curves of $\mathrm{r}$ and $\mathrm{K}$ populations in the simulation to the empirical observations described in the previous section. Figure $4 \mathrm{~d}$ shows that even when the initial proportion of $\mathrm{r}$ cells was highest $(r: K=9: 1)$ the extinction time of $r$ cells in the simulation with no between-cell type 
interaction ( $\alpha=\beta=0$; no effect of one cell population on the other) is approximately five times longer than observed. Simulations reveal that the extinction time of the $r$ cell population is shortened when $\alpha$ is higher than $\beta$ (Extended Data Figure 5). Comparing the growth curves from empirical observations (blue line in Figure 4d) and in simulations across values of $\alpha$ and $\beta$ (green and red lines in Figure 4d), we find that the values of $\alpha=2.2$ and $\beta=0$ fit the data best (Figure 4d, Extended Data Table 4). Thus, we infer that there is an interaction between $r$ and $\mathrm{K}$ cells and $\mathrm{K}$ cells influence $\mathrm{r}$ cell death.

\section{Phenotypic diversity promotes cancer cell population growth}

In silico -- To test whether the existence of phenotypic diversity and inter-population interaction promote total fitness, we first carried out stochastic simulations to compare the growth dynamics of $\mathrm{r}-\mathrm{K}$ mixed populations to pure $\mathrm{r}$ - and $\mathrm{K}$-cell assemblages. Unlike in the previous section, the current computational model considers space and density heterogeneity in the environment where the tumor cells grow, and the interaction of $\mathrm{r}$ and $\mathrm{K}$ cells in these conditions. The rates of cell division and death depend on local cell density. Due to the density effect, cells are able to divide and migrate only if there is sufficient nearby space. The simulation is described in detail in the Materials and Methods and Extended Data Figure 13. Figure $4 \mathrm{c}$ illustrates that in silico growth distribution of $\mathrm{r}$ and $\mathrm{K}$ cells in the mixed population is consistent with empirical observations (the upper panel of Figure 4c). Among-cell interaction and the density effect promote the re-localization of $\mathrm{r}$ and $\mathrm{K}$ cells, from well-mixed at the beginning of cell culture to a biased distribution with the entire occupation of the K cells in the middle and the outward spread of $r$ cells (the bottom panel of Figure 4c). The mixed populations exhibit significantly higher rate of growth than the pure r- or K-cell populations (Figure 5a and 5b).

In vivo - Mouse xenografts initiated with $r, K$, and $r-K$ mixed cells were weighed on the $34^{\text {th }}$ day, followed by $\mathrm{H} \& \mathrm{E}$ staining. The necrotic and non-necrotic regions were distinguished using the gray threshold method. We observed a high incidence of death in the r-xenografts (Figure 5c) and a significantly higher proportion of non-necrotic cells the mixed xenografts (Figure 5d). Although average fresh weight of the r-xenografts is much larger than the fresh weight of K- and mixed xenografts (reflecting the higher $\mathrm{r}$ cell proliferation rate, Figure 5e), the mean weight of viable cells in the mixed xenografts is the highest. It indicates that the 
existence of phenotypic trade-offs within a cell population is advantageous to cell viability and population growth.

\section{Discussion}

$242 r$-and $K$ - selection theory predicts that natural selection increases density-dependent rates of

243 population growth. This has been tested experimentally on specific model systems from 244 bacteria and Drosophila to vertebrates accounting for life history details ${ }^{15,70-73}$. The notion of trade-offs in life-history evolution became a prominent feature of the theory and prompted a focus of theoreticians and field scientists both in ecology and evolutionary biology $1,2,15,37,74$. However, the heart of continuing controversy on the theory of $r$-and $K$-selection between theoreticians and field biologists is that many complex life-history characters of natural populations contradict theoretical expectations ${ }^{1,4,5}$. It is unrealistic to expect that a theory could account for all aspects of the natural environment and its impact on evolutionary processes in all organisms ${ }^{1,5}$. Thus, the only proper way to test the theoretical predictions is in controlled settings congruent with the assumptions of the simple models.

Tumorigenesis is an evolving and dynamic process where highly genetically and phenotypically heterogeneous neoplastic cell populations persist in challenging environments. In fact hallmarks of cancer cannot be acquired in all cancer cells all the time ${ }^{75}$. An important cell-to-cell phenotypic variability is determined by several exterior and interior constrains ${ }^{12,76-}$ ${ }^{79}$. For instance, environments in tumors are both stable (but crowded, hypoxic, and nutrientpoor) in the interior, and fluctuating in nutrients, space, and interaction between the components in the microenvironment at the edge of the tumors ${ }^{80,81}$. The consequences of somatic cell evolution under complex environmental pressures parallel ecological processes in nature, with inevitable survival-reproduction trade-offs because organisms have to allocate limited resources among several functions that affect fitness. Neoplastic cells may also be subject to evolutionary trade-offs with respect to resource allocation and growth constraints $^{12,20,21,35}$. The mixture of biotypes that form cancer cell populations can be characterized by survival-proliferation trade-offs, and directly quantified in controlled environments in vitro. Carrying out experimental evolution under $r$-and $K$-selection in cancer cell lines, we observe that cancer cell populations face a survival-reproduction trade-off. $r$ cells 
the cost of their ability to propagate under crowded conditions, consistent with the central idea of the $r$ - and $K$-selection theory ${ }^{4}$.

Our analysis of pathway enrichment and expression of differentially expressed genes reflects phenotypic differences in cell proliferation, cell death, and adhesion between $\mathrm{r}$ and $\mathrm{K}$ cells in vitro and in vivo. We observe higher growth and death rates in $\mathrm{r}$ cells, compared to $\mathrm{K}$ cells (Figure 1d and 1g, Figure 2b). Additionally, adhesion junctions and focal adhesion affect adherence capability of cells. Since trypsin is frequently applied to dissociate adhesive cells from their substratum ${ }^{82}$, we performed a trypsinization assay to quantify cell adhesive ability (Extended Data Figure 6). Extended Data Figure 14 shows that it takes significantly longer to digest attached $\mathrm{K}$ than $\mathrm{r}$ cells, confirming that $\mathrm{K}$ cells are more prone to adhesion.

Cells with higher fitness tend to maintain a relatively high transcriptome stability ${ }^{83}$. Changes in transcriptional profiles reveal that $\mathrm{r}$ cells are much more sensitive to density change than $\mathrm{K}$ cells, consistent with the observation that $r$ cells have lower fitness at high density in competition assays (Figure 1b and 1c, Extended Data Figure 1a and 1b). Remarkably, differentially expressed genes that respond to density change in r cells are enriched in the cell cycle and DNA replication pathways (Extended Data Figure 7,8), suggesting that $r$ cells have different growth rates depending on culture conditions. This is consistent with direct measurements of growth rate at high and low density (Figure 1d).

Computer simulations which integrate of $r$ - and $K$-selection theory predictions and parameters of inter-cell interaction based on Lotka-Volterra models illustrate temporal and spatial dynamics of population growth of heterogeneous cell populations following $r$ - and $K$ strategies. The growth curves based on empirical data and mathematical models show that growth rates and fitness of $\mathrm{r}$ - and $\mathrm{K}$-selected cells follow the logistic equations predicted by theory. As density increases, $\mathrm{K}$ cells dominate mixed cell populations. Our simulations, fitted to empirical data, establish a competitive relationship between phenotypically diverse cancer cells. In the short term, competition can decrease whole-population fitness. However it triggers niche differentiation leading cell types to occupy different niches, thus maximizing the use of available resources in the ecosystem ${ }^{60}$. Interaction between tumor cells further improves the total fitness of a tumor in the long term (Figure 5).

\section{Materials and Methods}


The HeLa cell line was provided by the Cell Bank, Type Culture Collection Committee,

302 Chinese Academy of Sciences. The test for mycoplasma contamination was negative. The

303 HeLa-HPV18 single-nucleotide variants ${ }^{84}$ were identified in the cell line. The HeLa cells were

304 cultured in complete DMEM (Gibco) medium containing 10\% FBS (Gibco) and antibiotics

$305\left(100 \mu \mathrm{g} / \mathrm{mL}\right.$ streptomycin and 100 units $/ \mathrm{mL}$ penicillin, Sigma-Aldrich) at $37{ }^{\circ} \mathrm{C}$ in an 306 atmosphere of $5 \% \mathrm{CO}_{2}$.

307 Cell cryopreservation

308 Cells were first trypsinized using a $1 \mathrm{X}$ trypsin-EDTA solution at room temperature for three 309 minutes and suspended in complete growth medium. Suspended cells were collected by 310 centrifugation (1300 rpm, $5 \mathrm{~min}$ ) and resuspended in 1X PBS. PBS suspended cells were 311 collected by centrifugation (1300 rpm, $5 \mathrm{~min}$ ) and resuspended in cryopreservation medium.

312 The cryopreservation medium contains 10\% DMSO and 90\% FBS. Cryopreservation medium 313 suspended cells were pipetted into a cryopreservation vial gently, and placed into a $-80{ }^{\circ} \mathrm{C}$ 314 freezer. Finally, vials were transferred intoliquid nitrogen for long-term storage when 315 temperature decreased to $-40^{\circ} \mathrm{C}$.

316 Subculture and Single-cell isolation

317 Cells were washed with 1X PBS three times after discarding cell culture medium, and 318 trypsinized with $1 \mathrm{X}$ trypsin-EDTA solution at room temperature for three minutes. The 319 detached cells were suspended, divided, and transferred into plates. Single cells were sorted 320 into individual wells of 96-well plates by flow cytometry (BD) from a HeLa cell population. 321 After six hours, a microscopic examination was performed to ensure only one cell in a well.

Cells were transfected by Lentiviral vectors pLenti6.3-MCS-IRES-eGFP and pLenti6.3MCS-IRES-dsRed (Invitrogen). Approximately $5 \times 10^{6} \mathrm{HeLa}$ cells were incubated in a $10 \mathrm{~cm}$ dish with DMEM before transfection. After incubating for $24 \mathrm{~h}$, the DMEM medium was replaced by $10 \mathrm{~mL}$ transfection-mix-medium that contains $8 \mu \mathrm{g} / \mathrm{mL}$ polybrene and $10^{6} \mathrm{IU} / \mathrm{mL}$ 
hours, cells were washed with PBS three times. To select cells that stably express eGFP and DsRed, the transfected cells were cultured in DMEM medium with blasticidin $(10 \mu \mathrm{g} / \mathrm{mL})$ for at least four weeks.

\section{Density-dependent selection}

332 Evolution experimental system

333 The initial cell population (IN-cells) derived from a single cell which was randomly selected

334 from the HeLa cell line. When the population size of IN-cells reached $10^{7}$, it was randomly

335 divided into two sub-populations of equal size. Each of sub-population was labeled with

336 fluorescent proteins as described above. Density-dependent selection was performed on labeled 337 cells.

r-selection

339 Cells were cultured under low-density. To ensure low density, cells were seeded on the 340 surface of a $10 \mathrm{~cm}$ dish with approximately $128 \mathrm{cells} / \mathrm{cm}^{2}$. Every 120 hours when the 341 population density reached to about $4 \times 10^{3} \mathrm{cells} / \mathrm{cm}^{2}$, a subset of cells was transferred to a 342 new plate to keep a similar density as the original population $\left(128 \mathrm{cells} / \mathrm{cm}^{2}\right)$. Six replicates

343 (three with dsRed and three with eGFP) were maintained in this manner for almost 200 cell 344 generations (200 days). Samples from each population were cryopreserved in liquid nitrogen 345 every 40 days.

$346 \quad$ K-selection

347 Cells were cultured under high-density. To ensure high density, cells were seeded on the 348 surface of a $10 \mathrm{~cm}$ dish with approximately $10^{5}$ cells $/ \mathrm{cm}^{2}$. Every 72 hours, when the 349 population density reached to about $2.2 \times 10^{5} \mathrm{cells} / \mathrm{cm}^{2}$, a subset of cells was transferred to 350 a new plate to keep a similar density as the original population $\left(10^{5} \mathrm{cells} / \mathrm{cm}^{2}\right)$. Six replicates 351 (three with dsRed and three with eGFP) were maintained in this manner for almost 130 cell generations (200 days). Samples from each population were cryopreserved in liquid nitrogen every 40 generations. 


\section{Relative fitness assay}

355

356

357

358

359

360

361

362

363

364

365

366

367

368

369

370

371

372

373

374

375

376

377

378

To measure the relative fitness of two cell populations cultured under a specific cell density (routine-, r-, or K-), the two cell populations were mixed and cultured together. The proportions of the two populations were monitored by flow cytometry (BD, Ex/Em (nm): 346/442) once a subculture was performed. Time between two subcultures depended on the culture protocol. The higher fitness population is the one dominating the mixed population over time.

\section{Measurement of growth rate}

$$
\text { Population growth rate was estimated using the equation (1): }
$$

$$
\frac{d N(t)}{d t}=r N(t)
$$

where $d N(t)$ is the total number of cells at time $t$, and $r$ is a constant coefficient. To obtain a linear function, cell numbers were converted to base-2 logarithms. The least-squares method (LSM) was used to fit the linear regression with the slope (r) of the regression line estimating the growth rate.

\section{Soft agar colony formation assay}

Approximately 1,000 cells were suspended in a top layer of $0.4 \%$ soft agar (SeaPlaque Agarose, BMA products). The cell suspensions were then overlaid onto a bottom layer of $1 \%$ soft agar containing complete DMEM supplemented with 10\% FBS in six-well plates. After a week, colony number was counted. After three weeks, the images of colonies were collected to compare their diameters by microscopy.

\section{In vivo tumor growth}

Female BALB/c Nude mice were purchased from the Beijing Vital River Laboratory Animal Technology Co., Ltd. Mice were 5-10 weeks of age for all experiments and kept in germ-free environments in the Institute of Zoology, Chinese Academy of Science.

Five-week female BALB/c Nude mice were assigned randomly into cages upon arrival. INcells, r-cells, and K-cells were suspended in normal saline separately. $50 \mu \mathrm{L}$ cell suspension 
$379\left(2 \times 10^{5} \mathrm{Cells} / \mu L\right)$ was inoculated under the inguinal skin of the mice. For each type of cell 380 inoculation, three mice were randomly selected and sacrificed every week from the third week 381 after inoculation. Xenografts were collected for further analysis. Sample sizes were determined 382 empirically (based on experience of other investigators who did similar assays). The 383 experiments were not performed blind. All animal study protocols were reviewed and approved 384 by the review boards of the Institute of Zoology Animal Care and Use Committee, Chinese 385 Academy of Science (ethical approval reference number IOZ-20150061) and were conducted 386 in accordance with the National Institutes of Health Guidelines for the Care and Use of 387 Laboratory Animals. The maximal tumor diameter of $20 \mathrm{~mm}$ was permitted by Institute of 388 Zoology Animal Care and Use Committee, Chinese Academy of Science. None of the 389 experiments in this study exceeded this limit.

390 FACS analysis of G0/G1 phase and cell death/apoptosis

391 Cells were trypsinized and suspended in cold 1X PBS.Five $\mu \mathrm{L}$ propidium iodide (Sigma, P4170) was added to the suspension. Cells were incubated at $4{ }^{\circ} \mathrm{C}$ for 30 minutes. Stained cells were analyzed by flow cytometry (BD, Ex/Em (nm): 346/442). Data were collected from 10000 stained cells.

The Annexin V, Alexa Fluor ${ }^{\circledR} 350$ conjugate (Invitrogen, a23202) was used for apoptosis rate detection. Cells were trypsinized and diluted to $\sim 1 \times 106$ cells $/ \mathrm{mL}$ in the annexin binding buffer. Five $\mu \mathrm{L}$ annexin $\mathrm{V}$ conjugate was added to $100 \mu \mathrm{L}$ of the cell suspension. The cell suspension was incubated at room temperature for 15 minutes. After the incubation, $400 \mu \mathrm{L}$ annexin-binding buffer was added. The samples were kept on ice after mixing gently. The stained cells were analyzed by flow cytometry (BD, Ex/Em (nm): 346/442). Data were collected from 10000 stained cells. xenografts

The H\&E (haematoxylin and eosin) staining of tumor sections was used to detect necrotic cells ${ }^{85}$. First, we prepared the central H\&E staining section of a xenograft. The sections were then converted into digital images using Aperio Digital Pathology Slide Scanner (Leica). To 
and converted to gray scale (rgb2gray function in Matlab). Image contrast was enhanced using histogram equalization (histeq function in Matlab). We then adjusted image intensity values twice with parameters low_in $=0.1$ and high_in $=0.7$ (imadjust function in Matlab) and applied the 2-D median filtering to the image with the filtering parameters $m=5$ and $n=5$ (medfilt2 function in Matlab). Finally, we set grey scale value 90 as the threshold to distinguish the necrotic and non-necrotic areas of the image. The pixels in the tumor region with the grey scale value less than 90 were considered necrotic. The net weight of viable cells in a xenograft tumor was obtained by multiplying the total weight of a tumor by the proportion of the non-necrotic area.

\section{RNA-seq and data analysis}

Total RNA was isolated using the TRIzol reagent, as described by the manufacturer (15596018, Invitrogen). RNA-seq libraries were constructed and sequenced by Berry Genomics. RNA-seq NGS reads were aligned to the hg19 reference genome using the Mapsplice aligner (version 2.1.8) ${ }^{86}$ with default parameters. The gene-level expression levels

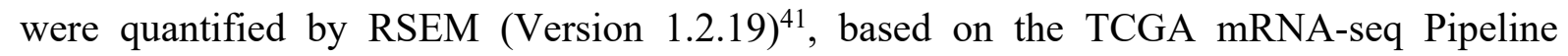
(https://webshare.bioinf.unc.edu/public/mRNAseq_TCGA/UNC_mRNAseq_summary.pdf).

Differentially expressed genes between samples were detected using EBSeq (Version 1.1.5) ${ }^{87}$ and were defined as the PPDE over 0.99. Gene set enrichment analysis of KEGG pathways was performed using the Functional Annotation Tool from DAVID with default parameters ${ }^{88,89}$. Expression perturbations in significant KEGG pathways were determined by GAGE ${ }^{46}$ with default parameters.

\section{Trypsinization assay}

Cells were seeded on a six-well plate. After 12 hours, we discarded the culture medium and washed the cells with cold PBS three times. $500 \mu \mathrm{L} 0.05 \%$ Trypsin was added into the well at room temperature. The plate was swayed softly and slowly 20 times. All supernatant (about $500 \mu \mathrm{L}$ ) was transferred into a new tube. We pipetted the supernatant gently to make sure most cells were single individuals. $400 \mu \mathrm{L}$ of the supernatant was put back on the plate to trypsinize the remaining cells. Finally, we estimated cell numbers in the $100 \mu \mathrm{L}$ of the remaining supernatant $\left(N_{1}\right)$ and among the remaining cells $\left(N_{2}\right)$ using a hemocytometer. The following equation was used to calculate the trypsinised cell ratio within a time interval: 


$$
\text { Ratio }=\frac{N_{1}}{N_{1}+N_{2}} \times 100 \%
$$

\section{Immunofluorescence assay}

Cells were seeded on coverslips. The coverslips were then placed on six-well plates. After a 48-hour incubation, cells were fixed with 4\% paraformaldehyde (PFA) in PBS for 20 minutes at room temperature, followed by blocking and permeabilizatuion for 30 minutes in blocking buffer, comprising $2 \%$ bovine serum albumin (BSA) and $0.2 \%$ Triton X-100 in PBS. Cells were incubated with the Yap1 antibody (GTX35195, GeneTex) for one hour, then with the FITC-conjugated goat anti-rabbit IgG $(\mathrm{H}+\mathrm{L})$ polyclonal antibody (GTX 77059, GeneTex) for 30 minutes. Both antibodies were diluted in PBS with 2\% BSA. Cell nuclei were stained with Hoechst 33342 (H3570, Invitrogen). Images were acquired using a Leica TCS SP8 confocal laser microscopy system (Leica Microsystems).

\section{Real-time quantitative PCR with reverse transcription}

Total RNA was isolated using the TRIzol reagent, as described by the manufacturer (15596018, Invitrogen). $1 \mu \mathrm{g}$ of RNA was used to generate cDNA with the High Capacity cDNA Reverse Transcription Kit (4368814, Applied Biosystems). Real-time quantitative PCR was performed to amplify cDNA by using Maxima STBR Green/ROX qPCR Master (K0223, Thermo Scientific) in a CFX96 Touch Real-Time PCR Detection System (Bio-Rad). The average threshold cycle $(\mathrm{Ct})$ of quadruplicate reactions was determined and amplification was analyzed by the $\Delta \Delta \mathrm{Ct}$ method. Gene expression was normalized to that of GAPDH. Real-time quantitative PCR with reverse transcription data were representative of at least three independent experiments, with two technical replicates per experiment. Primer sequences used to amplify human DLG2 and GAPDH as follows:

$$
\text { human DLG2 forward: CAATGGGATGGCAGACTTTT; }
$$

human DLG2 reverse: ACAGCTCGGTGGAGAAACAT;

human GAPDH forward: ACAGCCTCAAGATCATCAGC; human GAPDH reverse: ATGGACTGTGGTCATGAGTC. 
siRNAs (Lipofectamine 3000 transfection reagent) were used to knock down the expression of DLG2. To check the knockdown efficiency, total RNA was isolated and quantified by quantitative PCR (qPCR) three days after transfection. The target sequences used to knock down human DLG2 are as follows:

K cells with dsRed and $\mathrm{r}$ cells with eGFP were mixed together equally. Cell density of the mixture population was about $2 \times 10^{6}$ cells $/ \mathrm{mL}$. $500 \mu \mathrm{L}$ of cell mixture was loaded on the central surface of an empty culture plate. After five minutes, the plate was put back to the incubator. When all cells attached (almost two hours), sufficient complete growth medium was added to the plate. Microscopic fluorescent field images of the plate were collected using imageXpress XLS (Molecular Devices) every three days. Image data were analyzed following the pipeline in the imageXpress XLS data analysis software (Molecular Devices).

481 Density dependent population dynamics can be predicted using a variety of mathematical models $^{90,91}$. The logistic and Gompertz growth models are most frequently used ${ }^{92,93}$. To determine which mathematical model is suitable for us to predict cell population dynamics, we

484 first obtained cell population dynamics data over eight days via the MTT cell proliferation assay, then fit population dynamics curves to three models: Logistic, Gompertiz, and 486 Exponential (Extended data Figure 9). We created a nonlinear model for cell population growth 487 based on the data from the MTT assay (fitnlm function in Matlab). The adjusted $r$-squared value of the logistic growth curve is 0.856 , the Gompertz -0.828 , and exponential -0.739 . 
491 We chose the Lotka-Volterra (L-V) model to investigate population dynamics cell type mixtures ${ }^{64,94}$. We assume that the cell population 1 and cell population 2 are two sub-types of cells from the same population. These two types of cells compete for the same resources in a mixted population. The competitive Lotka-Volterra equations are

$$
\left\{\begin{array}{l}
\frac{d x_{1}}{d t}=R_{01} x_{1}\left(1-\frac{N_{t}+\alpha x_{2}}{C_{1}}\right) \\
\frac{d x_{2}}{d t}=R_{02} x_{2}\left(1-\frac{N_{t}+\beta x_{1}}{C_{2}}\right)^{\prime}
\end{array}\right.
$$

496

497

498

499

500

501

502

503

504

505

506

507

508

509

510

511

512

513

514

515

where $x_{i}$ is the size of the ith population; $R_{0 i}$ is the inherent per-capita growth rate, and $C_{i}$ is the carrying capacity. $\alpha$ represents that the additional effect of cell population 2 on cell population 1 and $\beta$ represents the additional effect cell population 1 on cell population $2 . N_{t}$ represents the total cell number at time $t$. Note, the meanings of $\alpha$ and $\beta$ are slightly different from the competitive coefficients in the general Lotka-Volterra equations. $\alpha+1$ and $\beta+1$ are equivalent to competitive coefficients in the general Lotka-Volterra equations.

Per-capita growth rate $\left(\mathbf{R}_{\mathbf{0}}\right)$ estimation: The inherent per-capita growth rate of every cell must be known at the beginning as the population growth model calculates the growth rate of every cell and its progenitors separately. It is an easy way to evaluate the inherent per-capita growth rate of every cell at the beginning via random sampling if the inherent per-capita growth rate distribution of a cell population is known. We isolated 141 single cells from the K-cell population and 100 single cells from the r-cell population and cultured them separately in wells of 96-well plates. Cells were counted every day for each clone over five days. The growth each cell over five days is considered exponential because cell density is very low.

Growth rate was estimated using the equation 4:

$$
\frac{d N(t)}{d t}=r N(t)
$$

where $d N(t)$ is the total number of cells at time $t$, and $r$ is a constant. To obtain a linear function, cell numbers were converted to base-2 logarithms. The least-squares method (LSM) was used to fit the linear regression in which the slope $(r)$ of the regression line estimates the growth rate. 
We assume that mutations do not drastically affect the growth rate immediately. Therefore, $r$ is equivalent to the $R_{0}$ of the initial single cell. We assume that the growth rate of any given

518 type of cell comes from a specified normal distribution. We estimate distribution parameters

519 from empirical growth rates of $141 \mathrm{~K}$ cells (for $\mathrm{K}$ cell simulations) and from $111 \mathrm{r}$ cells.

520 (Extended Data Table 5).

521 The distribution of the inherent per-capita growth rate of a cell population is $522 R_{0} \sim \operatorname{Norm}\left(\mu, \sigma^{2}\right)$ and lies within the interval $R_{0} \in(-\infty,+\infty)$. The parameters of the inherent 523 per-capita growth rate distributions are estimated using the function 'normfit' in MATLAB. 524 The fitted distributions are $D R_{0 r} \sim \operatorname{Norm}\left(1.1832,0.2441^{2}\right)$ and $D R_{0 K} \sim \operatorname{Norm}\left(0.6823,0.3764^{2}\right)$.

526 Carrying capacity (C) estimation: Given the logistic cell population growth curve, carrying 527 capacity can be estimated using the logistic growth function. We seeded $\mathrm{r}$ and K cells separately 528 on six-well plates separately and assessed population size every 24 hours. The initial population size was $1.5 \times 10^{3}$ cells (Extended Data Figure 10).

Since apoptotic cells could not be distinguished when the cell counting was performed each day, cell number may have been over-estimated. Severity of over estimation of r-cell number grows as cell density increases because these cells go into apoptosis at a high rater as conditions become crowded. It is necessary to correct the estimation of carrying capacity to eliminate the effect of apoptotic cells on cell count. The carrying capacity could be corrected by

$$
C_{\text {cor }}=C_{\text {est }}\left(1-r_{\text {apo }}\right)
$$

where the $\mathrm{C}_{\text {cor }}$ represents the corrected carrying capacity, $\mathrm{C}_{\mathrm{est}}$ represents the estimated carrying capacity via curve fitting, $r_{a p o}$ represents the $r$ - or K-cell apoptosis rate under high density (data were collected via FACS analysis of cell apoptosis).

The carrying capacity of $\mathrm{r}$ cells was estimated as $C_{r}=1.937 \times 10^{4} \mathrm{cells} / \mathrm{cm}^{2}$ and of $\mathrm{K}$ cells as $C_{K}=2.2216 \times 10^{4}$ cells $/ \mathrm{cm}^{2}$.

$\boldsymbol{\alpha}$ and $\boldsymbol{\beta}$ estimation: $\alpha$ and $\beta$ directly influence population size. Cell growth rates can decrease rapidly $\alpha$ and $\beta$ are both large, leading to population sizes far beyond carrying capacity. However, empirical observations did not show significant reduction of population size when

$544 \quad r$ - and $K$-cell were mixed together at high density. It suggests that either $\alpha$ or $\beta$ is very small. 
545 The $\mathrm{r}$ - and $\mathrm{K}$ cells co-cultural assays suggest that $\mathrm{K}$ cells may have a higher competitive ability

546 (Figure 4). This inference indicates that $\beta$ should be near 0 . Here we assume that $\beta$ is between

$547 \quad 0$ and 0.5 and $\alpha$ between 0.5 and 3 .

548 First, we use a grid-search scheme, all parameter pairs traversed with intervals 0.5 , to 549 estimate the $\alpha$ and $\beta$. We predict the dynamics of an $r$ and $K$-cell mixture population using the 550 density-dependent growth model with set values of $\alpha$ and $\beta$. Other parameters were fixed. We 551 then calculated Pearson correlation coefficients between predictions and observations. These correlations are maximized when $(\alpha, \beta)=(2.5,0)$. This fit is better than when $(\alpha, \beta)=(2,0)$ or $(\alpha, \beta)=(3,0)$ (Extended Data Table 4$)$. The correlation values increase and then decrease within the interval $\alpha \in[2,3]$ when $\beta=0$. This suggests that the values of $\alpha$ between 2 to 3 and $\beta=0$ maximize the agreement between simulations and data.

We next repeated the grid-search scheme, traversing values of $\alpha$ between 2 and 3 with intervals of 0.1 and setting $\beta=0$. The final estimates are: $\alpha=2.2$ and $\beta=0$ (Extended Data Figure 5;11, Extended Data Table 4).

Cell population dynamics of the mixed population with among-cell competition are based on the values of $C_{r}, C_{K}, C_{r} / \alpha$ and $C_{K} / \beta$. WE estimate $\mathrm{C}_{\mathrm{r}}=1.937 \times 10^{4}$ cells $/ \mathrm{cm}^{2}, \mathrm{C}_{\mathrm{K}}=$ $2.2216 \times 10^{4}$ cells $/ \mathrm{cm}^{2}, \alpha=2.2$, and $\beta=0$. Thus, $C_{r} / \alpha=9.685 \times 10^{3}$ and $C_{K} / \beta$ is infinite.

562 Here $C_{K}>C_{r} / \alpha$ and $C_{r}<C_{K} / \beta$ indicate that $\mathrm{r}$ cells would eventually go extinct when 563 competing with $\mathrm{K}$ cells $\mathrm{s}^{95}$.

\section{Spatial growth model}

565 Tumor cells living in a limited space cannot move freely. Among-cell interactions are also 566 confined to a limited space, precluding interaction when between-cell distance is large. Given these considerations, we assume that there is a cell-centric limited space for every cell where the density-dependent effects which impact the central cell are confined. We call this densitydependent space (DDS; for more details see Stochastic simulation of cell growth with spatial structure). carrying capacity is much greater than its size. However, if carrying capacity is small, early- 
573

574

575

576

577

578

579

580

581

582

583

584

585

586

587

588

589

590

591

stage population size increase results in a drastic decrease in growth rate. Carrying capacity is related to the size of the habitat. In a DDS, the maximum carrying capacity is 36 (Extended Data Figure 13, methods: Carrying capacity estimation of spatial growth model). Here we use $C_{s}$ to represent the carrying capacity in a DDS. Because the $C_{s}$ value is very small (compare to $C$ in equations (3)), the equations (1) are not applicable to predict the dynamics of $\mathrm{r}$ - and $\mathrm{K}$ cell mixed population using the spatial growth model. In addition, only when cell density exceeds a certain threshold, do the cells become subject to density-dependent growth. A reasonable value of the threshold is $\frac{C_{s}}{2}$ as the population growth rate achieves its maximum when the population size reaches $\frac{C_{s}}{2}$.

For two cell sub-populations, we let

$$
X_{1}=N_{t}+\alpha x_{2}
$$

$$
X_{2}=N_{t}+\beta x_{1}
$$

where $X_{1}$ represents the practical population size which determines the density-dependent growth rate of population $1 ; X_{2}$ is defined similarly for population 2 .

When $X_{1} \leq \frac{C_{s 1}}{2}$, the growth rate of population 1 is equal to its inherent growth rate, and similarly for population 2 when $X_{2} \leq \frac{C_{s 2}}{2}$. For population 1, we have

$$
1-\frac{\lambda\left(C_{s 1}-\frac{C_{s 1}}{2}\right)}{C_{s 1}}=0
$$

Where the $\lambda$ is a constant. By solving the equations 7 , we get $\lambda=2$. The final equations are

$$
\left\{\begin{array}{ll}
\frac{d x_{1}}{d t}=R_{01} x_{1} & X_{1} \leq \frac{C_{s 1}}{2} \\
\frac{d x_{1}}{d t}=R_{01} x_{1}\left(1-\frac{2\left(N_{t}+\alpha x_{2}\right)-C_{s 1}}{C_{s 1}}\right) & X_{1}>\frac{C_{s 1}}{2} \\
\frac{d x_{2}}{d t}=R_{02} x_{2} & X_{2} \leq \frac{C_{s 2}}{2} \\
\frac{d x_{2}}{d t}=R_{02} x_{2}\left(1-\frac{2\left(N_{t}+\beta x_{1}\right)-C_{s 2}}{C_{s 2}}\right) & X_{2}>\frac{C_{s 2}}{2}
\end{array} .\right.
$$

592 Carrying capacity estimation of the spatial growth model: In the spatial model, we assume that 593 the density-dependent space (DDS) is a square area which contains 36 grid coordinates (6X6 
594 grids, Extended Date Figure 10). Because the carrying capacity of $K$-cells is 1.147 times that

595 of $r$-cells $\left(\frac{C_{K}}{C_{r}} \approx 1.147\right.$; more details see the carrying capacity estimation), in a DDS the 596 carrying capacity of $K$-cells is $C_{s K}=36$ (the maximum number for the region), and of $r$-cells 597 is $C_{s r}=31$.

598 Stochastic simulation of population growth of $\mathrm{r}$ and $\mathrm{K}$ cells in co-cultures

599 Cells in culture are subject to artifacts, such as subculture. A subculture is performed when cell

600 density exceeds a threshold (roughly $70 \%$ to $90 \%$ confluent) and is used to maintain cell density.

601 The subculturing procedure includes recommended split-ratios and cultural medium

602 replenishment schedules. A realistic in silico cell culture model should take into account such

603 artifacts. The details of the stochastic simulation procedures are as follows:

604 Initiation: We assign the initial inherent per-capita growth rate to every cell on initialization.

605 Here we assumed that growth rates of cells in a population come from a normal distribution.

606 Every cell is assigned an initial growth rate sampled from its growth rate distribution (see the 607 per-capita growth rate estimation for details). To avoid outliers, random sampling was based 608 on a truncated distribution (within the interval $R_{0} \in(\mathrm{Q} 1, \mathrm{Q} 3)$ ) of the inherent per-capita 609 growth rate. Q1 is the lower quartile and Q3 the upper quartile of the observed growth rate 610 distribution respectively (Extended Data Table 5). The initial population size was chosen 611 according to culturing methods being simulated and followed experimental conditions.

612 Population growth and sub-culture: Cell division is based on growth rate. Each cell in a 613 population, enters the division stage only if the cell growth rate is over 0 . In the stochastic 614 simulation, the time of a cell cycle (CT) was defined as

$$
C T=24 / R
$$

616 where the $R$ represents the growth rate of a cell calculated from the density-dependent 617 population growth model. CT is measured in hours. The biological meaning of $R$ is the number 618 of cell divisions within 24 hours. Considering the characteristics of the cell cycle, the time of 619 interphase of mitosis occupies nearly $90 \%$ of the entire cycle ${ }^{96}$. Thus, cell division time (DT) 620 is:

$$
D T=0.9 \cdot C T+\operatorname{geornd}(1 /(0.1 \cdot C T)),
$$


where geornd means a random number sampled from a geometric distribution. If the time since the last cell division is greater than DT, the cell divides into two cells. When the culture time exceeds 72 hours ( $K$-selection conditions), subculture was performed. Population size was reduced to the initial population size during subculture by random selection. After subculture, cells continue to grow in silico.

Six mixed populations with different $\mathrm{r}$ - and $\mathrm{K}$-cell initial proportions ( $\mathrm{r}: \mathrm{K}=99: 1, \mathrm{r}: \mathrm{K}=9: 1$, $\mathrm{r}: \mathrm{K}=7: 3, \mathrm{r}: \mathrm{K}=1: 1, \mathrm{r}: \mathrm{K}=3: 7, \mathrm{r}: \mathrm{K}=1: 9)$ were simulated. 100 simulations were performed for each population type (Extended Data Figure 12).

631 Tumor cells live in a spacially heterogeneous environment ${ }^{97,98}$. The distribution of cell density 632 within a tumor should therefore be non-uniform. Spatial structure plays an important role in 633 population dynamics ${ }^{31,61,99-105}$. In a given cell growth space, if the real-time location of cells 634 can be determined, the spatial structure of the whole population can be described. For this reason, we constructed a two-dimensional lattice-based growth space where physiological activities such as cell growth and migration are carried out. The location of cells is determined by grid coordinates. (Extended Data Figure 13)

To simulate the population dynamics of cells which grow on a two-dimensional surface as realistically as possible, we considered the following factors that can influence spatial structure: cellular morphological characteristics, cell migration, cell proliferation, and cell death.

641 In-silico cellular morphology: The growth of cells on a two-dimensional surface may result 642 in regional differences in cell density due to uneven cell distribution or different growth rates

643 (Extended Data Figure 14a). In other words, the density-dependent spatial heterogeneity exists 644 in the cell growth environment. In addition, space occupied by cells varies under different 645 densities. In a low-density environment, cells occupy a larger area, increasing cell surface to 646 maximize contact with the culture medium. Because of crowding, cells are arranged closely. 647 The attachment area of a cell decreases in a high-density environment (Extended Data Figure 648 14b). Therefore, we assume cells have two in-silico morphological types: large cell, 649 corresponding to cells growing in a low density environment, occupying four coordinate grid; small cell, corresponding to cells growing in high density environment, occupying one coordinate grid (Extended Data Figure 13). The in silico cellular morphology can be 
transformed between large and small cells. When there is an empty coordinate around a small cell that can accommodate a large cell, the small cell preferentially transforms into a large cell. A large cell will switch its morphology to two small cells via cell division when and only when there is no space around it that can accommodate two large cells, and there is space to accommodate two small cells.

657 Cell migration: Cells migrate with a certain rate in their growth space. When a migration event occurs, the coordinates of cells in the growth space change once, and the migration must occur to adjacent coordinates (Extended Data Figure 13). The migration direction of each step is assumed random. Cells differ in their migration speed. $\mathrm{r}$ cells migrate more readily than $\mathrm{K}$ cells, as measured by a trans-well migration assay. The mean migration speed of $\mathrm{r}$-cells is close to five times higher than K cells (Extended Data Figure 15). Here we assume that the migration speed follows a beta distribution. The parameter "a" of the beta distribution is 5 . The expected migration speed of $\mathrm{r}$ cells is 0.5 and of $\mathrm{K}$ cells is 0.1 .

Cell proliferation: A division event can only be completed in two adjacent coordinates. Cells retain their original cellular morphology during division. If there is no space to proliferate, small cells die.

Cell death: When a cell dies, its original coordinate is marked as empty and can be occupied by another cell via cell division or migration. Death occurs if a cell that must divide but has no space to do so, or if a cell is affected by high density (calculated by Equations (9)).

Density-dependent space: Density-dependent space (DDS) is a square region containing 36 grids (6X6 grids). A cell can be in the center (large cells) or on the grid coordinate $(3,3)$ whose origin is the top-left of the DDS grid (small cells). We assume that only the cells located in the DDS contribute the density effects to the central cell (Extended Data Figure 13).

Simulation process: The simulation program of cell growth with spatial structure is divided into two processes: initiation and population growth. In the initiation process, cells were loaded in the center of the growth space. All cells were clustered together to form a circle community.

678 This constructs a density-dependent spatially heterogeneous environment for cell growth. The outside space low-density, while inside the cell community is a relatively high-density environment. The inherent per-capita growth rate (Normal distribution; the same as the initiation process in the stochastic simulation of cell growth with subculture) and migration speed (Beta distribution) of each cell were initiated with random sampling. Finally, the 
program calculates a constant variable $\delta$ t, which represents the minimal time interval that can contain a migration event. In the population growth process, the migration and proliferation of cells depend on the migration rate and the density growth rate (calculated by Equations (9)). The migration rate and the inherent per-capita growth rate were maintained between mother and daughter cells. The program iterates all cells and calculates their density growth rates. $\delta \mathrm{t}$ is the time interval between iterations.

Cells were suspended and seeded at the concentration of 500 cells/well in 96-well plate. A volume of $20 \mu \mathrm{l}$ dissolved MTT was pipetted into each well. After incubating for $4 \mathrm{~h}$ at $37^{\circ} \mathrm{C}$ in a humidified $\mathrm{CO}_{2}$ incubator, the medium was removed and $200 \mu 1$ sterile DMSO was added to each well. Absorbance values were then read at $570 \mathrm{~nm}$ with a microplate spectrophotometer.

694 The proliferation of living cells was monitored based on absorbance values. polycarbonate membrane filters $(8-\mu \mathrm{m}$ pore size) for 24 -well plates. Briefly, cells were digested with $0.05 \%$ trypsin, and suspended in a FBS-free DMEM culture medium. Cells were then plated into the upper chamber $(3 \times 103$ cells/well $)$. At the same time, $650 \mu \mathrm{L}$ of DMEM with $10 \%$ FBS was added to the lower chamber of the well and the plates were incubated for five hours at $37{ }^{\circ} \mathrm{C}$ with $5 \% \mathrm{CO}_{2}$. After incubation, cells on the upper surface of the membranes were removed gently with cotton swabs. Cells that had entered the lower surface of the filter membrane were stained with $0.1 \%$ Hoechst 33342 (H3570, Invitrogen) for 30 minutes at room temperature, and washed three times with PBS. Four randomly selected fields in each well were image captured with the ImageXpress Micro HCS (Molecular Devices), and migrated cells were counted. $\mathrm{n}=3$ independent experiments.

Statistical analyses were performed using R. Student's $t$-test and Wilcoxon test were used for calculating significance of between-group differences. Statistical significance is indicated by $\mathrm{P}<0.05$. All data were expressed as mean \pm s.d. of at least three independent experiments. 


\section{References}

712 1. Parry, G. D. The meanings of r-and K-selection. Oecologia 48, 260-264 (1981).

713 2. Pianka, E. R. On r- and K-Selection. The American Naturalist 104, 592-597 (1970).

714 3. Don, C. S. G., Sonchifolia, E. \& Dc, L. On r- And K- Selection Theory : Life History Strategy of Emilia. 3, $715 \quad 35-39(2013)$.

716

717

718

719

720

721

722

723

724

725

726

727

728

729

730

731

732

733

734

735

736

737

4. Reznick, D. N., Bryant, M. . M. J. \& Bashey, F. r - AND K -SELECTION REVISITED : THE ROLE OF POPULATION REGULATION IN LIFE-HISTORY EVOLUTION Special Feature. Ecology 83, 15091520 (2002).

5. Long, T. \& Long, G. The effects of $\mathrm{r}$ and $\mathrm{K}$ selection on components of variance for two quantitative traits. Genetics 76, 567-573 (1974).

6. Greaves, M. \& Maley, C. C. Clonal evolution in cancer. Nature 481, 306-313 (2012).

7. Korolev, K. S., Xavier, J. B. \& Gore, J. Turning ecology and evolution against cancer. Nat. Rev. Cancer 14, 371-380 (2014).

8. Tabassum, D. P. \& Polyak, K. Tumorigenesis: It takes a village. Nat. Rev. Cancer 15, 473-483 (2015).

9. Shibata, D. Heterogeneity and tumor history. Science (80-. ). 336, 304-305 (2012).

10. Wodarz, D. \& Komarova, N. L. Dynamics of Cancer. (2014). doi:10.1142/8973

11. Jacqueline, C. et al. Cancer : A disease at the crossroads of trade- - offs. 215-225 (2017). doi:10.1111/eva.12444

12. Aktipis, C. A., Boddy, A. M., Gatenby, R. A., Brown, J. S. \& Maley, C. C. Life history trade-offs in cancer evolution. Nat. Rev. Cancer 13, 883-892 (2013).

13. Silvertown, J. Demons in Eden: The Paradox of Plant Diversity. (University of Chicago Press, 2008).

14. Law, R. Optimal Life Histories Under Age-Specific Predation. Am. Nat. 114, 399-417 (1979).

15. Stearns, S. Trade-offs in life-history evolution. Funct. Ecol. 3, 259-268 (1989).

16. Cain, M. L., Bowman, W. D. \& Hacker, S. D. Ecology. (Sinauer, 2014).

17. Stearns, S. C. THE EVOLUTION OF LIFE HISTORY TRAITS : A Critique of the Theory and a Review of the Data. Critique (1977).

18. Williams, G. C. Pleiotropy, Natural Selection, and the Evolution of Senescence. Evolution 11, 398 (1957). 
20. Hayakawa, S. No cancer in cancers: Evolutionary trade-off between successful viviparity and tumor escape from the adaptive immune system. Med. Hypotheses 66, 888-897 (2006). prevalence of non-Darwinian cell evolution. Proc. Natl. Acad. Sci. 113, E663-E663 (2016). Microevolutionary Process. Annu. Rev. Genet. 50, 347-369 (2016).

24. Li, C. et al. A direct test of selection in cell populations using the diversity in gene expression within tumors. Mol. Biol. Evol. 34, 1730-1742 (2017).

25. Merlo, L. M. F., Pepper, J. W., Reid, B. J. \& Maley, C. C. Cancer as an evolutionary and ecological process. Nat. Rev. Cancer 6, 924-935 (2006).

26. Frank, S. a. Dynamics of Cancer. Incidence, Inheritance, and Evolution. Dynamics of Cancer. Incidence, Inheritance, and Evolution (2007). doi:10.1053/j.gastro.2010.01.058

28. Nowak, M. A. EcologyEvolutionary dynamics: exploring the equations of life. (Harvard University Press, 2006, 2006).

29. Crespi, B. \& Summers, K. Evolutionary biology of cancer. Trends Ecol. Evol. 20, 545-552 (2005).

30. Basanta, D. \& Anderson, A. R. A. Exploiting ecological principles to better understand cancer progression and treatment. Interface Focus 3, (2013). (2009).

32. Hendry, A. P. Key questions in the genetics and genomics of eco-evolutionary dynamics. Heredity (Edinb). 111, 456-466 (2013).

33. Maley, C. C. et al. Classifying the evolutionary and ecological features of neoplasms. Nat. Rev. Cancer 17, 605-619 (2017). biology. Evol. Appl. 2, 62-70 (2009). 
trade-offs affect cancer evolution. (2018).

768

36. Mueller, L. D. Density-Dependent Population Growth and Natural Selection in Food-Limited Environments: The Drosophila Model. Am. Nat. 132, 786-809 (1988).

37. MacArthur, R. H. \& Wilson, E. O. The Theory of Island Biogeography. Science 159, 71-72 (1968).

38. Lansing, E., Velicer, G. J. \& Lenski, R. E. Evolutionary Trade-Offs under Conditions of Resource Abundance and Scarcity : Experiments with Bacteria. Ecology 80, 1168-1179 (1999).

39. Velicer, G. J. \& Lenski, R. E. Evolutionary Trade-Offs under Conditions of Resource Abundance and Scarcity : Experiments with Bacteria Published by : Ecological Society of America EVOLUTIONARY TRADE-OFFS UNDER CONDITIONS OF RESOURCE ABUNDANCE AND SCARCITY : EXPERIMENTS WITH BACTERIA. America (NY). 80, 1168-1179 (2010).

40. Southwood, T. R. E., May, R. M., Hassell, M. P. \& Conway, G. R. Ecological Strategies and Population Parameters. Am. Nat. 108, 791-804 (1974).

41. Li, B. \& Dewey, C. N. RSEM: Accurate transcript quantification from RNA-Seq data with or without a reference genome. BMC Bioinformatics 12, (2011).

42. Li, B., Ruotti, V., Stewart, R. M., Thomson, J. A. \& Dewey, C. N. RNA-Seq gene expression estimation with read mapping uncertainty. Bioinformatics 26, 493-500 (2009).

43. He, C. \& Klionsky, D. J. Regulation Mechanisms and Signaling Pathways of Autophagy. Annu. Rev. Genet. 43, 67-93 (2009).

44. Pearson, G. et al. Mitogen-Activated Protein ( MAP ) Kinase Pathways : 22, 153-183 (2001).

45. Brown, E. J. \& Schreiber, S. L. A signaling pathway to translational control. Cell 86, 517-20 (1996).

46. Luo, W., Friedman, M. S., Shedden, K., Hankenson, K. D. \& Woolf, P. J. GAGE: Generally applicable gene set enrichment for pathway analysis. BMC Bioinformatics 10, 1-17 (2009).

47. Kim, S., Chin, K., Gray, J. W. \& Bishop, J. M. A screen for genes that suppress loss of contact inhibition: identification of ING4 as a candidate tumor suppressor gene in human cancer. Proc. Natl. Acad. Sci. U. S. A. 101, 16251-6 (2004).

48. Takai, Y., Miyoshi, J., Ikeda, W. \& Ogita, H. Nectins and nectin-like molecules: Roles in contact inhibition of cell movement and proliferation. Nat. Rev. Mol. Cell Biol. 9, 603-615 (2008).

49. Gumbiner, B. M. \& Kim, N.-G. The Hippo-YAP signaling pathway and contact inhibition of growth. J. Cell Sci. 127, 709-717 (2014).

50. Halder, G. \& Johnson, R. L. Hippo signaling: growth control and beyond. Development 138, 9-22 (2011). 
51. Zhao Li, L., Lei, Q. and Guan, K. L., B. The Hippo-YAP pathway in organ size control and tumorgenesis: an updated version. Genes Dev. 24, 862-874 (2010).

52. Yu, F. X. et al. Regulation of the Hippo-YAP pathway by G-protein-coupled receptor signaling. Cell 150, 780-791 (2012).

53. Yu, F. X. \& Guan, K. L. The Hippo pathway: Regulators and regulations. Genes Dev. 27, 355-371 (2013).

54. Bao, Y., Hata, Y., Ikeda, M. \& Withanage, K. Mammalian Hippo pathway: From development to cancer and beyond. J. Biochem. 149, 361-379 (2011).

55. Dunn, B. \& Ma, X. The dark side of hippo signaling: A cancer promoter role. Fly 11, 271-276 (2017).

56. Chen, C. \& Halder, G. The Hippo Signaling Pathway and Cancer. 307-325 (2013). doi:10.1007/978-1$4614-6220-0$

57. Chen, C.-L., Schroeder, M. C., Kango-Singh, M., Tao, C. \& Halder, G. Tumor suppression by cell competition through regulation of the Hippo pathway. Proc. Natl. Acad. Sci. 109, 484-489 (2012).

58. B., Z. et al. Angiomotin is a novel Hippo pathway component that inhibits YAP oncoprotein. Genes Dev.

$$
\text { 25, 51-63 (2011). }
$$

59. Humbert, P. O. et al. Control of tumourigenesis by the Scribble $/ \mathrm{Dlg} / \mathrm{Lgl}$ polarity module. Oncogene 27, 6888-6907 (2008).

60. Hardin, G. The Competitive Exclusion Principle. Science 131, 1292-1297 (1960).

61. Orlando, P. A., Gatenby, R. A. \& Brown, J. S. Tumor Evolution in Space: The Effects of Competition Colonization Tradeoffs on Tumor Invasion Dynamics. Front. Oncol. 3, 1-12 (2013).

62. Steiner, C. F. Impacts of density-independent mortality and productivity on the strength and outcome of competition. Ecology 86, 727-739 (2005).

63. Lotka, A. J. Contribution to the Mathematical Theory of Capture: I. Conditions for Capture. Proc. Natl. Acad. Sci. U. S. A. 18, 172-8 (1932).

64. Lotka, J. Natural Selection as a Physical Principle. Proc. Natl. Acad. Sci. U. S. A. 8, 151-154 (1922).

65. Sprott, J. C., Vano, J. A., Wildenberg, J. C., Anderson, M. B. \& Noel, J. K. Coexistence and chaos in complex ecologies. Phys. Lett. Sect. A Gen. At. Solid State Phys. 335, 207-212 (2005).

66. Holzer, M. \& Scheel, A. A slow pushed front in a Lotka-Volterra competition model. Nonlinearity 25, 2151-2179 (2012).

67. Muhammadhaji, A., Teng, Z. \& Rehim, M. On a Two Species Stochastic Lotka-Volterra Competition 
68. Kingsland, S. Alfred J. Lotka and the origins of theoretical population ecology. Proc. Natl. Acad. Sci. 112, 9493-9495 (2015).

69. He, X. \& Ni, W. M. Global dynamics of the Lotka-Volterra competition-diffusion system with equal amount of total resources, II. Calc. Var. Partial Differ. Equ. 55, 1-20 (2016).

70. Url, S., Society, B. E., Archive, T. J. \& Archive, T. J. Trade-Offs in Life-History Evolution S. C. Stearns. 3, 259-268 (2008).

71. Creighton, J. C. C., Heflin, N. D. D. \& Belk, M. C. C. Cost of Reproduction, Resource Quality, and Terminal Investment in a Burying Beetle. Am. Nat. 174, 673-684 (2009). melanogaster. J. Insect Physiol. 43, 501-512 (1997). central trade-off between growth rate and cellular robustness. Mol. Biol. Cell 22, 4435-4446 (2011).

74. Soskine, M. \& Tawfik, D. S. Mutational effects and the evolution of new protein functions. Nat. Rev. Genet. 11, 572-582 (2010).

75. Floor, S. L., Dumont, J. E., Maenhaut, C. \& Raspe, E. Hallmarks of cancer: Of all cancer cells, all the time? Trends Mol. Med. 18, 509-515 (2012).

76. Nourmohammad, A. et al. Gene expression variability across cells and species shapes innate immunity. Nature 563, 197-202 (2018).

77. Spencer, S. L., Gaudet, S., Albeck, J. G., Burke, J. M. \& Sorger, P. K. Non-genetic origins of cell-to-cell variability in TRAIL-induced apoptosis. Nature 459, 428-432 (2009). (2005).

79. Warner, A. E., Guthrie, S. C. \& Gilula, N. B. Antibodies to gap-junctional protein selectively disrupt junctional communication in the early amphibian embryo. Nature 311, 127-131 (1984). 
(2010).

83. López-Maury, L., Marguerat, S. \& Bähler, J. Tuning gene expression to changing environments: From rapid responses to evolutionary adaptation. Nat. Rev. Genet. 9, 583-593 (2008).

84. Meissner, J. D. Nucleotide sequences and further characterization of human papillomavirus DNA present in the CaSki, SiHa and HeLa cervical carcinoma cell lines. J. Gen. Virol. 80, 1725-1733 (1999).

85. Degenhardt, K. et al. Autophagy promotes tumor cell survival and restricts necrosis, inflammation, and tumorigenesis. Cancer Cell 10, 51-64 (2006). Acids Res. 38, 1-14 (2010).

87. Leng, N. et al. EBSeq: An empirical Bayes hierarchical model for inference in RNA-seq experiments. Bioinformatics 29, 1035-1043 (2013).

88. Huang DW, B. T. S., Lempicki, R. A. \& others. Systematic and integrative analysis of large gene lists using DAVID bioinformatics resources. Nat. Protoc. 4, 44-57 (2008).

89. Huang, D. W., Sherman, B. T. \& Lempicki, R. A. Bioinformatics enrichment tools: Paths toward the comprehensive functional analysis of large gene lists. Nucleic Acids Res. 37, 1-13 (2009). Human Mortality, and on a New Mode of Determining the Value of Life Contingencies. Philos. Trans. ofthe R. Soc. London 115, 513-583 (1825).

93. Verhulst, P. F. Recherches mathématiques sur la loi d'accroissement de la population. Nouv. mémoires l'Académie R. des Sci. B.-lett. Bruxelles 14-54 (1845). (1926). Cybern. 48, 201-211 (1983). 
886 98. Hao, J.-J. et al. Spatial intratumoral heterogeneity and temporal clonal evolution in esophageal squamous 887 cell carcinoma. Nat Genet 48, 1500-1507 (2016).

888 99. Chen, J., Sprouffske, K., Huang, Q. \& Maley, C. C. Solving the puzzle of metastasis: The evolution of cell 889 migration in neoplasms. PLoS One 6, (2011).

890 100. Tang, L. et al. Computational modeling of 3D tumor growth and angiogenesis for chemotherapy 891 evaluation. PLoS One 9, 1-12 (2014).

892 101. Waclaw, B. et al. Spatial model predicts dispersal and cell turnover cause reduced intra-tumor 893 heterogeneity. Nature 525, 261-267 (2015).

894 102. Düchting, W. \& Vogelsaenger, T. Three-dimensional pattern generation applied to spheroidal tumor 895 growth in a nutrient medium. Int. J. Biomed. Comput. 12, 377-392 (1981).

896 103. Hao, J.-J. et al. Spatial intratumoral heterogeneity and temporal clonal evolution in esophageal squamous 897 cell carcinoma. Nat. Genet. 48, 1500-1507 (2016).

898 104. Duchting, W. Spatial Structure of Tumor Growth : A Simulation Study. 292-296 (1980).

899 105. Robertson-Tessi, M., Gillies, R. J., Gatenby, R. A. \& Anderson, A. R. A. A. Impact of metabolic

900 heterogeneity on tumor growth, invasion, and treatment outcomes. Cancer Res. 75, 1567-1579 (2015). 
a

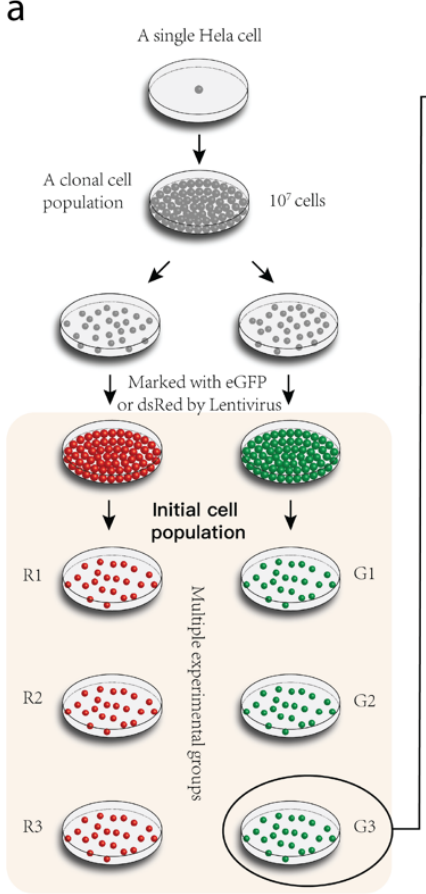

d

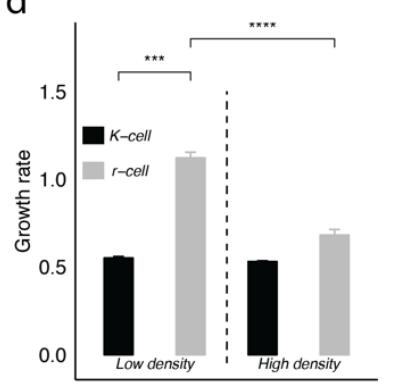

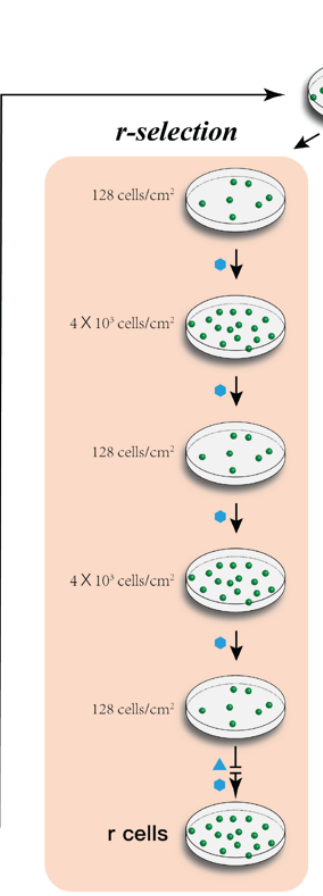

e

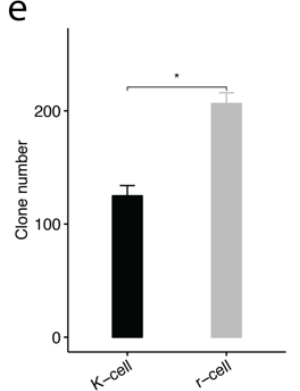

b
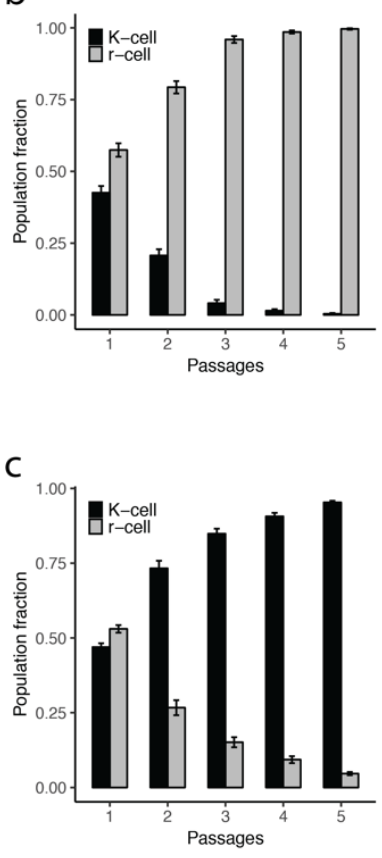

f
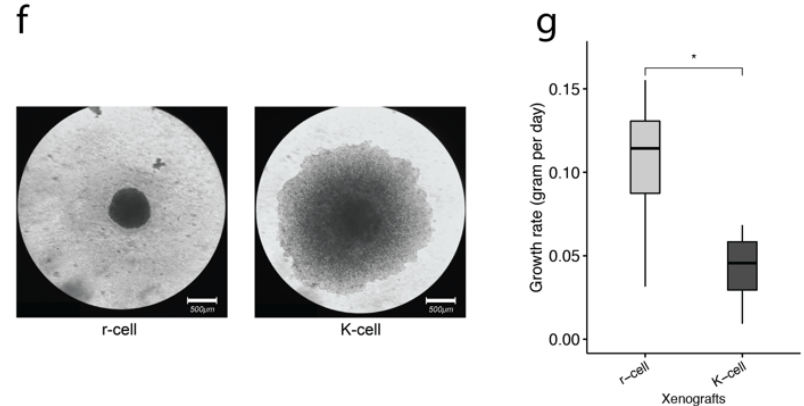

Figure $1 \mid r$ - and $K$-selection in HeLa cells and their growth rate cells in 2D and 3D cultures. a) $\boldsymbol{r}$ - and $\boldsymbol{K}$-selection strategies. An initial single cell clone was split into six populations, with three labeled with dsRed (R; red dots) and three with eGFP (G; green dots). Each cell culture was passaged $>200$ times at low ( $r$-selection) and high ( $K$-selection) density. Fitness tests were performed at b) low and c) high density. The Y-axis is the proportion of $r$ and $K$ cells estimated by flow cytometry during five passages ( $\mathrm{x}$-axis) of $\mathrm{r}-\mathrm{K}$ mixed cell cultures. $\mathbf{d})$ The growth rate of $\mathbf{r}$ and $K$ cells across culture conditions. Cells in $111 \mathrm{r}$ - and $141 \mathrm{~K}$-cell clones were counted every 24 hours. Growth rate is calculated based on cell number change within seven days. The tumorigenicity of $\mathbf{r}$ and $K$ cells is presented based on the number e) and size f) of tumor clones in a soft agar assay on the 7th $21 \mathrm{st}$ day. g) The growth rate of $\mathbf{r}$ - and K-cell xenografts. Error bars represent standard deviations. Dash lines separate culture conditions or strategies. Error bars represent standard deviations. Student's t-test: $* \mathrm{P}<0.05, * * \mathrm{P}<0.01, * * * \mathrm{P}<0.005, * * * * \mathrm{P}<0.0001$. Scale bars in $\mathbf{f})$ represent $500 \mu \mathrm{m} . \mathrm{n}=3$ independent experiments per population in $\mathrm{b}$ ), c), d), and e); $n=12$ xenografts in $\mathrm{g})$. mean $\pm \mathrm{SD}$. 

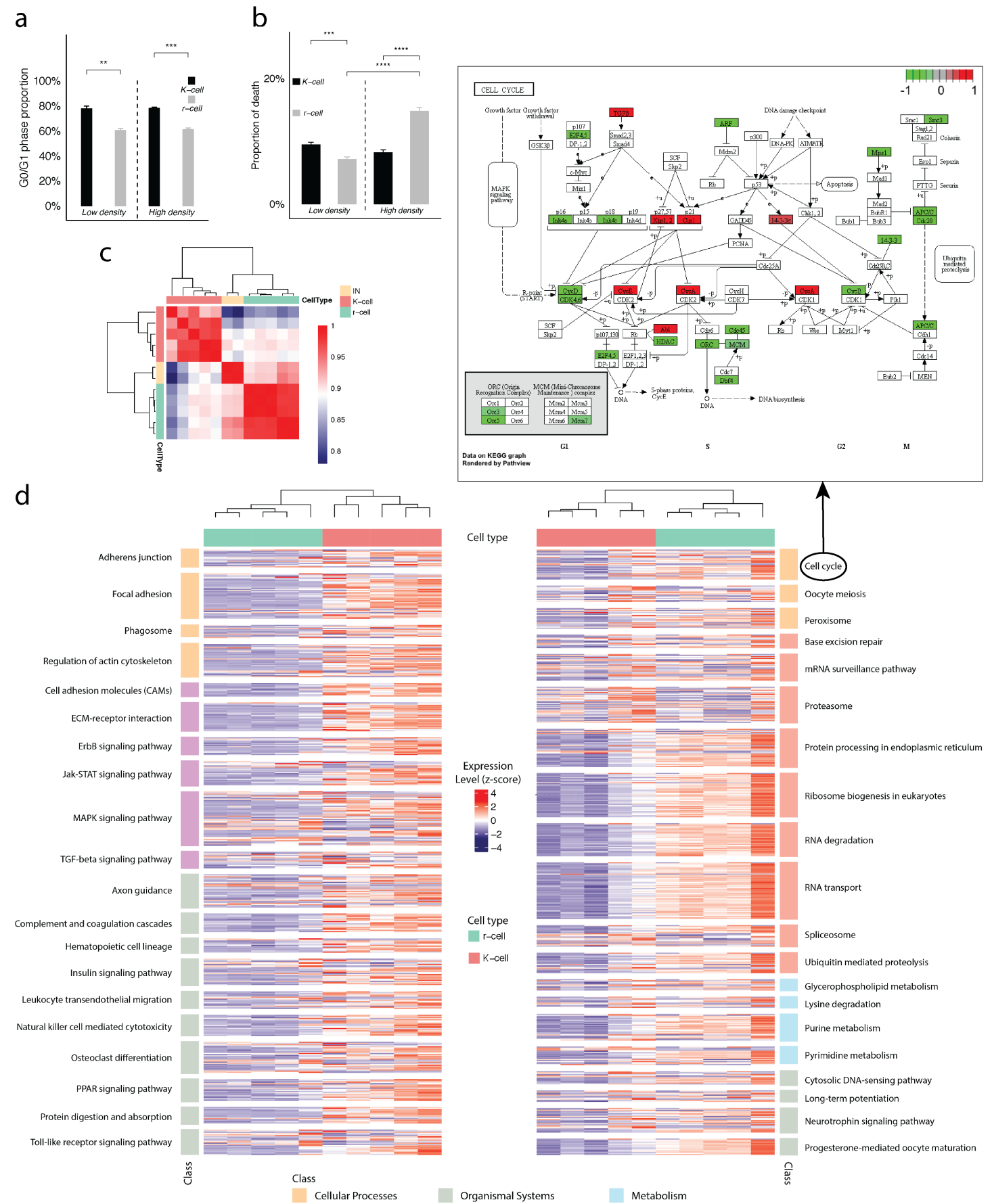

920 a) The G0/G1 phase proportion and b) the proportion of cell death in $r$ (gray) and K cells (black) are analyzed using PI and Annexin V staining via flow cytometry under high- and low-density conditions. Dashed lines separate culture conditions. Error bars represent standard deviations. Student's t-test: $* \mathrm{P}<0.05, * * \mathrm{P}<0.01, * * * \mathrm{P}<0.005, * * * * \mathrm{P}<0.0001 . \mathrm{n}=3$ independent experiments per population. c) Gene expression correlation between IN, r-, and K-cell populations. d) Pathways that show significantly different expression between $\mathbf{r}$ and $\mathbf{K}$ cells. The left panel presents signaling pathways that are overexpressed in five K-cell populations (pink), the right presents pathways overexpressed in five r-cell populations (green). The z-score heatmap indicates the scale of gene expression difference. The upper panel shows the cell cycle pathway with relatively over- (red) and under- (green) expressed genes in $\mathrm{r}$ vs. K cells highlighted. 
a
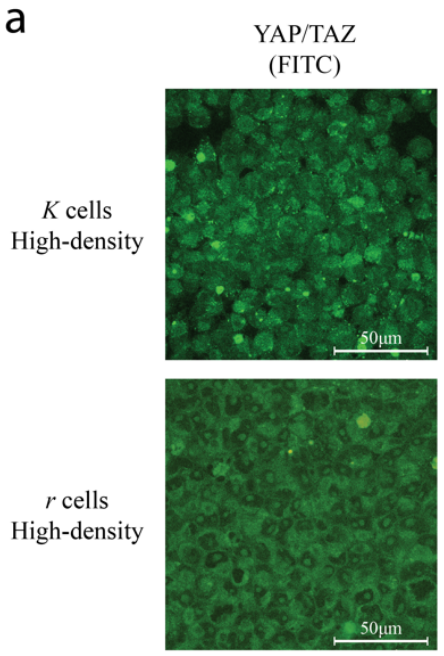

Nucleus

(Hochest)
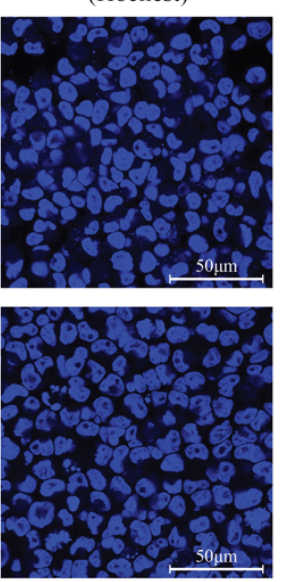

b

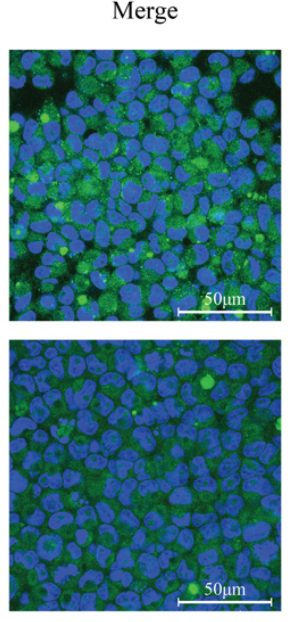

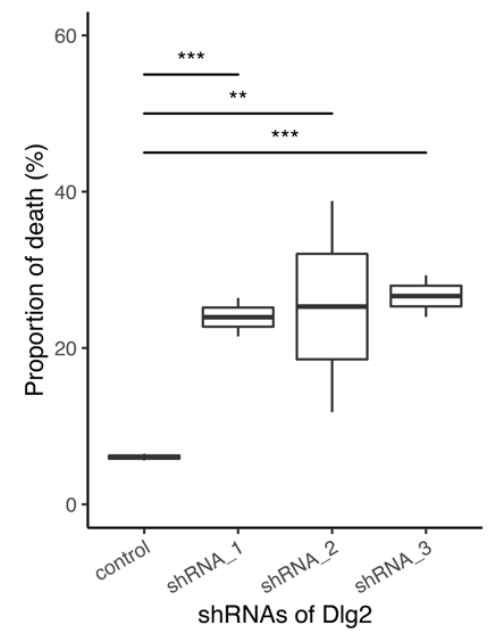

Figure 3 | YAP/TAZ colocalization in $r$ and $K$ cells under high density andthe effect of Dlg-2 knock-down in K cells. a) YAP/TAZ colocalization in the cytoplasm and nuclei under high density. YAP/TAZ was immunofluorescently stained with FITC. Hoechst staining marks nuclei. Scale bars represent $50 \mu \mathrm{m}$. b) The proportion of cell death in Dlg-2 knockdown $K$ cells under high density. The death rate was measured by Annexin V staining via flow cytometry. Student's $t$-test: ${ }^{*} \mathrm{P}<0.05, * * \mathrm{P}<0.01, * * * \mathrm{P}<0.005 . \mathrm{n}=8$ independent experiments per population mean $\pm \mathrm{SD}$. 
a

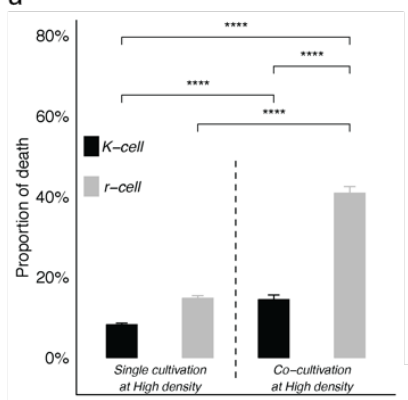

d

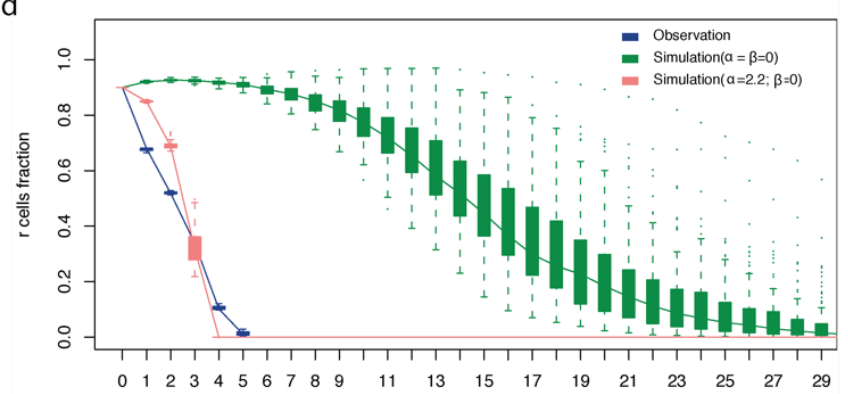

b

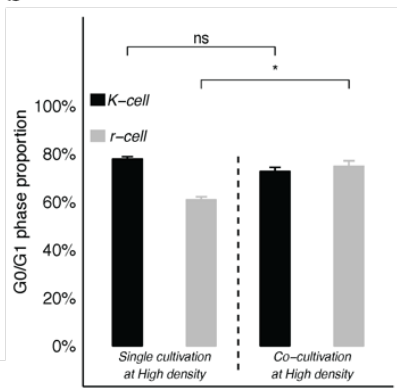

Passages c

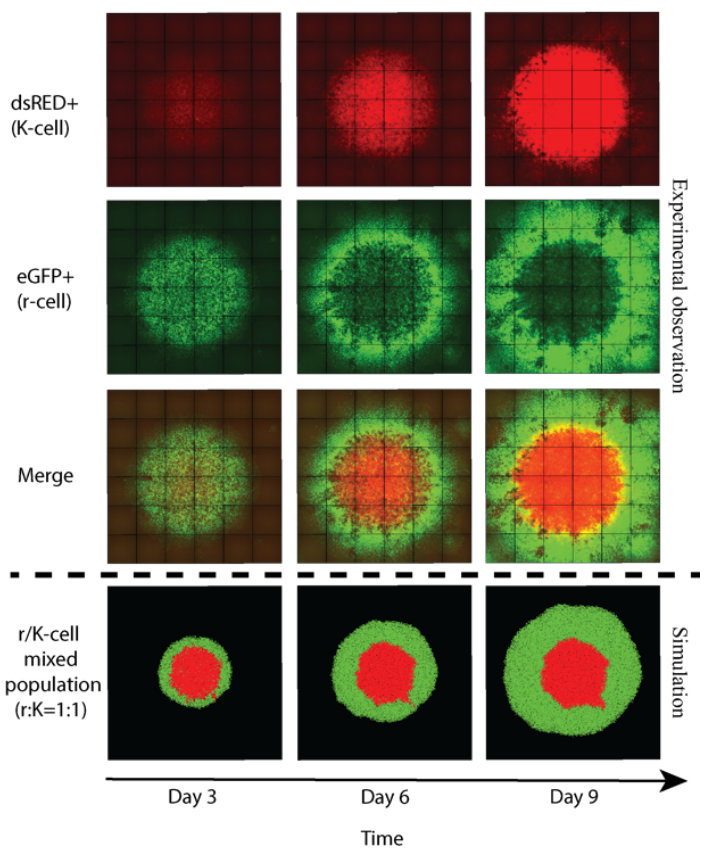

Figure 4 | Inter-population interaction and temporal and spatial growth of $r$ and $K$ cells in mixed populations. a) Cell death and b) G0/G1 phase proportion of $r$ and $K$ cells in individual and mixed cultures. The $y$-axis in a) and b) shows death rates and G0/G1 phase proportion of $r$ (gray) and K (black) cells. Death rates were measured by Annexin V staining. G0/G1 phase proportions were measured by PI staining via flow cytometry. Cells were cultured alone or co-cultivated at high density. Dashed lines separate culture strategies. Error bars represent standard deviations. Student's t-test: ns: non-significant, ${ }^{*} \mathrm{P}<0.05$, $* * * * \mathrm{P}<0.0001 . \mathrm{n}=3$ independent experiments per population. c) Spatial structure in an $\mathbf{r}-\mathbf{K}$ mixed population. $\mathrm{K}$ and $\mathrm{r}$ cells are well mixed in equal proportion and seeded in the center of a six-well plate with total cell number $\sim 10^{6}$. Each column represents time points from day 3 to day 9 after cell seeding. $r$ and $\mathrm{K}$ cells are eGFP and dsRed positive shown in green and red, respectively. The top and bottom panels show the spatial distribution of $r$ and $\mathrm{K}$ cells in empirical observations and computer simulations, respectively. d) The distribution of $\mathbf{r}$ cell fractions estimated in vitro (blue) and in silico $(\operatorname{red}(\alpha=2.2, \beta=0)$ and green $(\alpha=\beta=0)$ ). The co-culture of $r$ and $K$ cells is initiated with $r / K$ ratio of $9: 1$. The $y$-axis reflects the fraction of $r$ cells in the co-culture; $x$-axis represents cell passages. $(n=100$ stochastic simulations per population; $\mathrm{n}=3$ independent experiments; mean $\pm \mathrm{SD}$ ). 
a

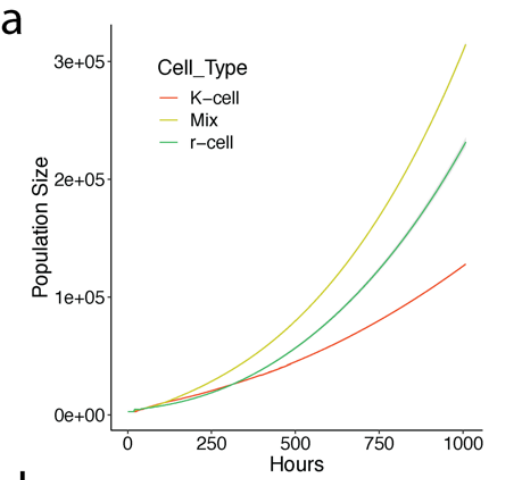

d

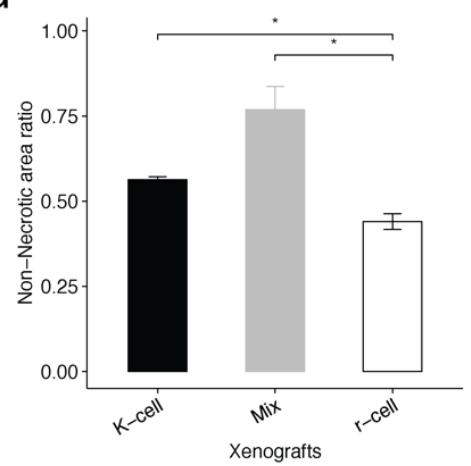

b
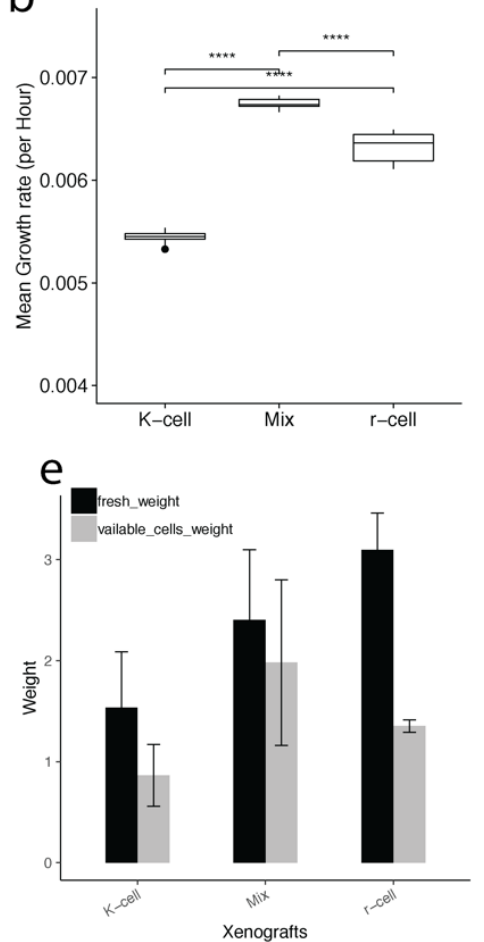

C
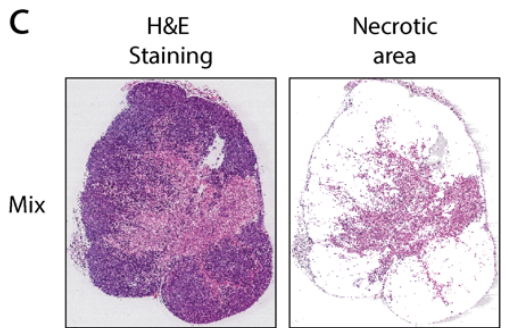

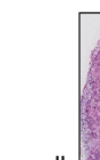
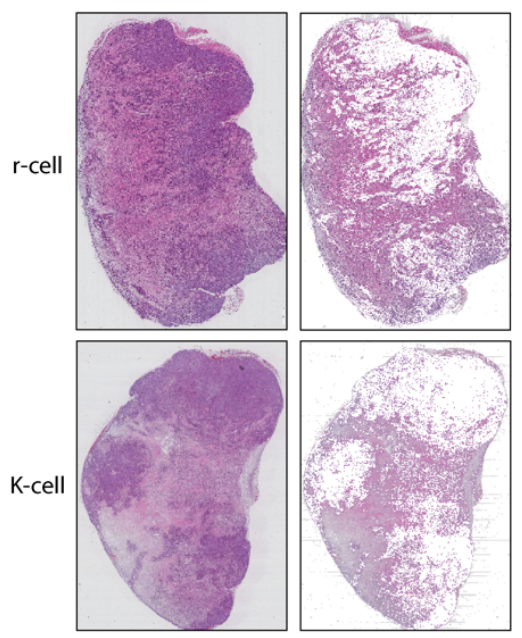

Figure 5 | Populartion fitness of $\mathbf{r}, \mathbf{K}$, and $\mathbf{r} / \mathbf{K}$ mixtures. a) Growth curves for different populations from the spatial computational model. The yellow line represents the r-cell population, the green line represents the mixture population of $\mathrm{r}$ - and $\mathrm{K}$ - cells and the red line represents the $\mathrm{K}$-cell population. The $\mathrm{Y}$-axis represents population size. The $\mathrm{X}$-axis represents time. $(\mathrm{n}=100$ stochastic simulations per population; mean $\pm \mathrm{SD})$. b) Mean growth rate comparison among populations. The growth rate was measured at 1 hour intervals. The $\mathrm{Y}$-axis represents mean growth rate. The $\mathrm{X}$-axis represents time. $(\mathrm{n}=100$ stochastic simulations per population; mean $\pm \mathrm{SD}$, Student's t-test: $* * * * \mathrm{P}<0.0001)$. c) Necrotic area detection. The second column represents the necrotic area in xenografts. d) Proportion of the non-necrotic area (y-axis) in xenografts. e) Whole tumor (black) and viable cell (gray) weight in xenografts. The xenografts were extracted at the sixth week after cell inoculation. $\mathrm{n}=6$ for each xenograft type; Student's t-test: $* \mathrm{P}<0.05, * * * * \mathrm{P}<0.0001$. 
a

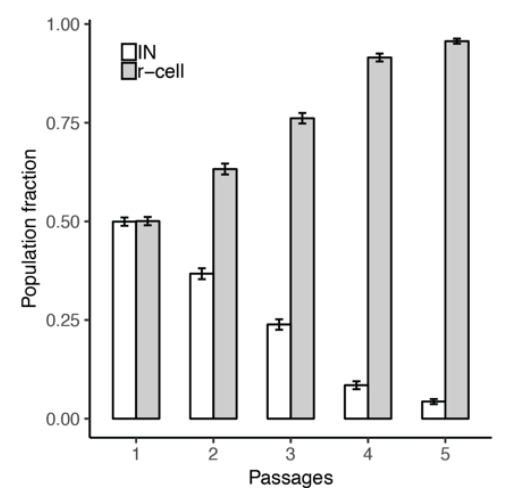

b

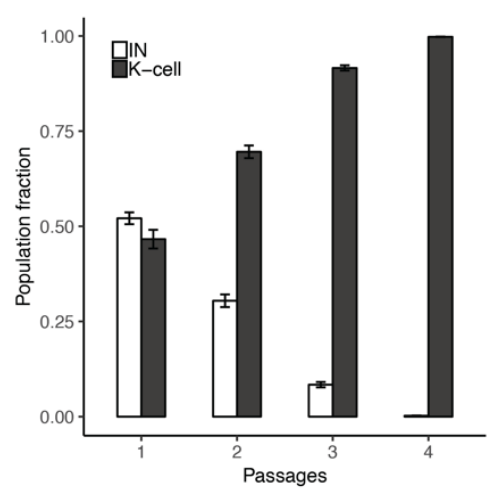

974
Extended Data Figure 1 | Fitness, growth, and apoptosis rates of $r$ - and K-cells in 2D and 3D environments. IN cells and the a) r-cells or b) K-cells were mixed together at equal amounts at the beginning. The mixed populations were cultured under normal culture conditions. The proportion of each type of cells was measured by flow cytometry every two days during subculture. Error bars represent standard deviations. $\mathrm{N}=3$ independent experiments per population, mean $\pm \mathrm{SD}$. 


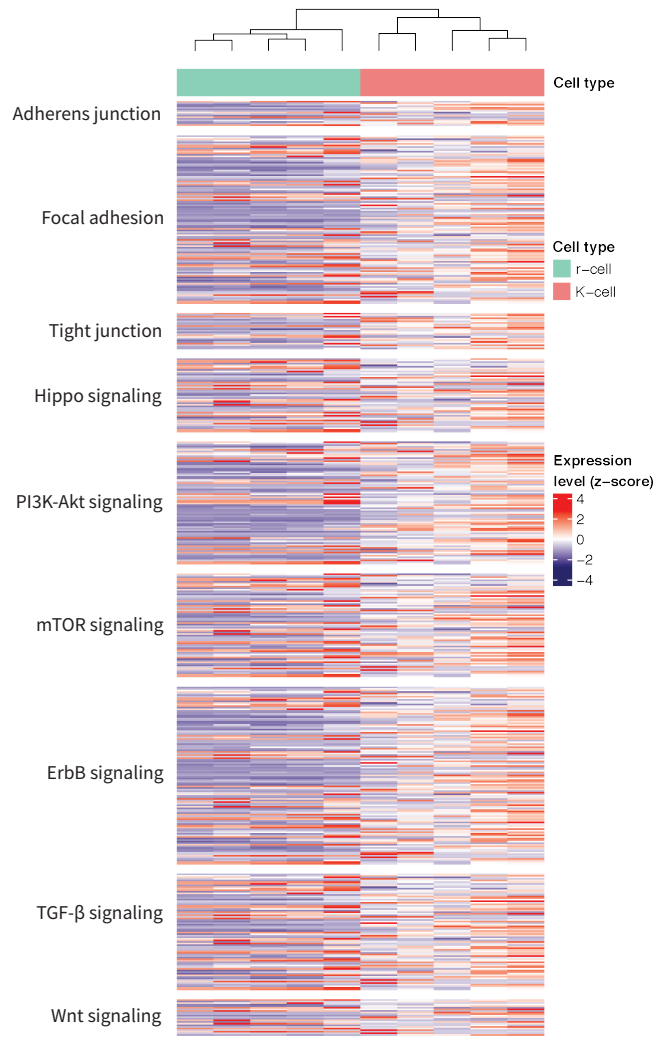


a
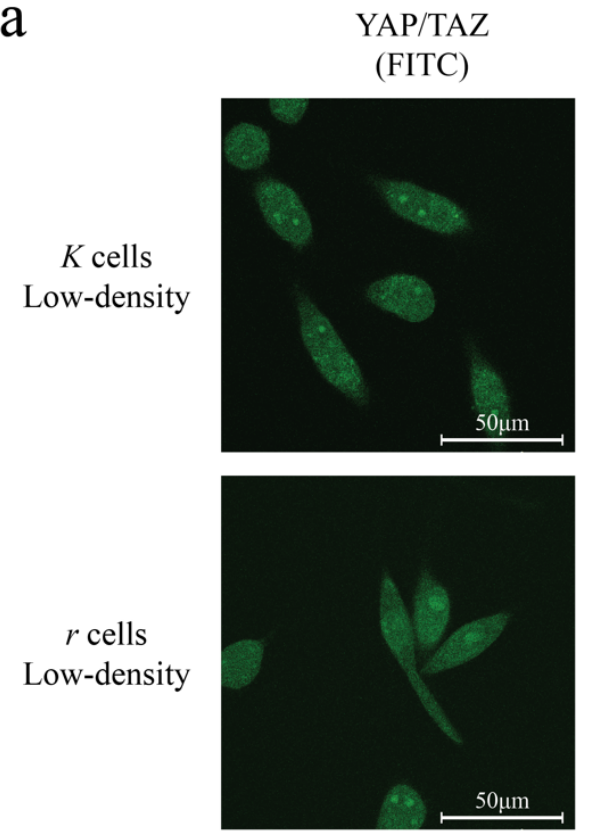

b

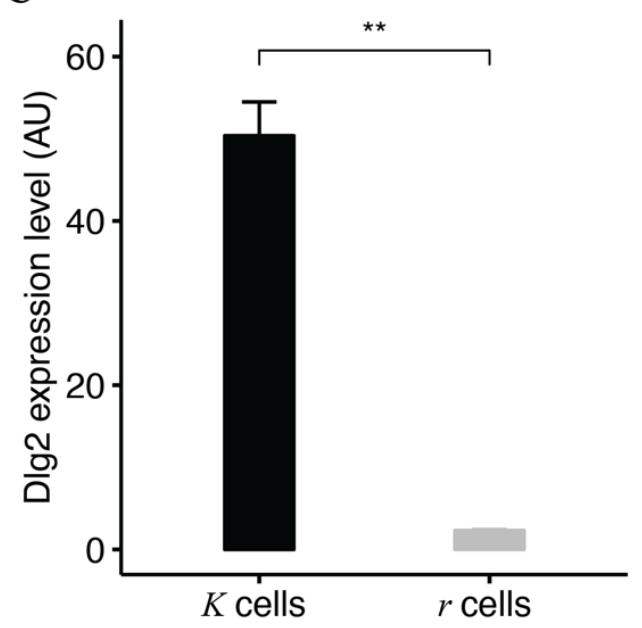

Nucleus

(Hochest)
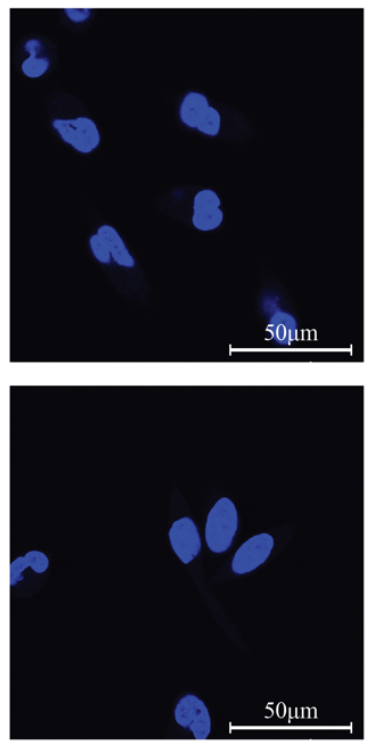

$\mathrm{C}$

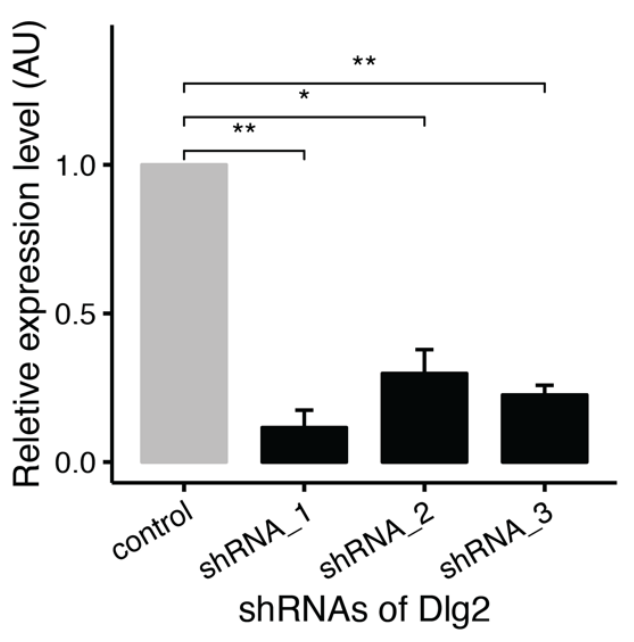
and shRNA knockout of Dlg-2 in $\mathbf{K}$ cells. a) YAP/TAZ colocalization in the cytoplasm and nuclei at low density. YAP/TAZ were stained with FITC by immunofluorescence. Positive Hoechst staining marks nuclei. Scale bars represent $50 \mu \mathrm{m}$. b) The expression level of Dlg-2 in $\mathrm{r}$ and $\mathrm{K}$ cells at high density by q-PCR. c) Dlg-2 shRNA in K cells. Three shRNAs were 


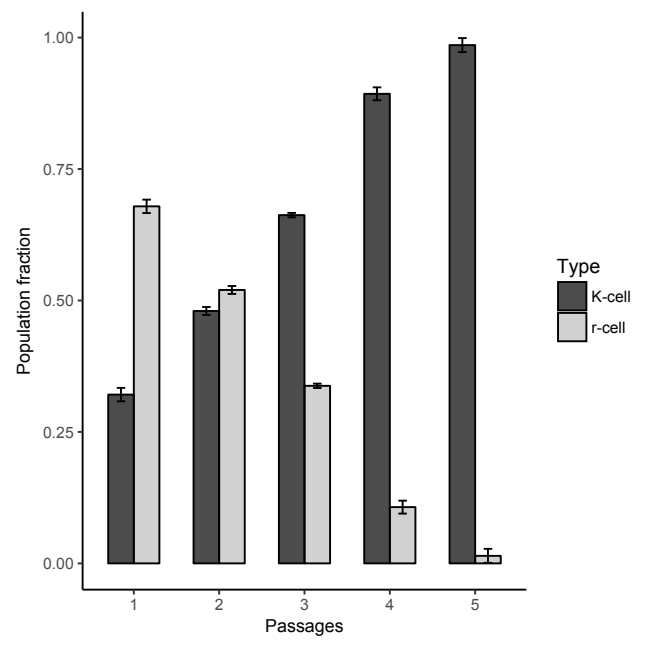

994 Extended data Figure 4 | Observed dynamics of mixted populations initiated with 90\%

995 r-cells and 10\% K-cells. Mixed populations were cultured under K-selection. The proportion 996 of each type of cells was measured by flowcytometry every three days during. The bars 997 represent the proportion change of cell population by time. The grey bars represent $r-$ and 998 black bars K-cells. The x-axis represents subculture times, the y-axis represents cell-type 999 proportions. Three replicates were performed on each assay. Error bars represent standard 1000 deviations. $\mathrm{n}=3$ independent experiments per population, mean $\pm \mathrm{SD}$. 
a

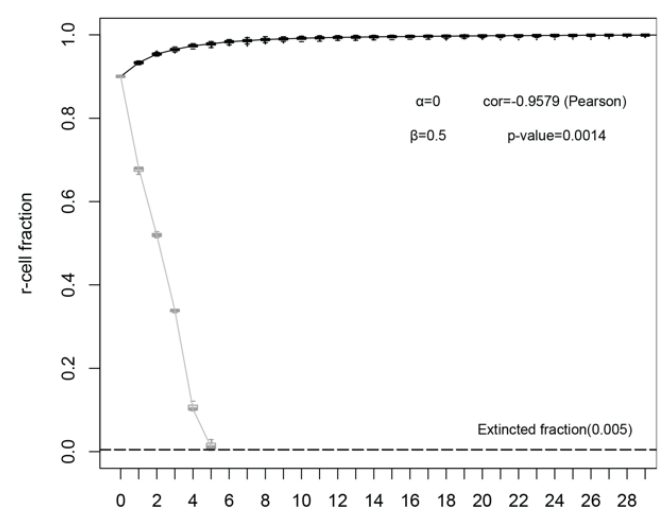

C

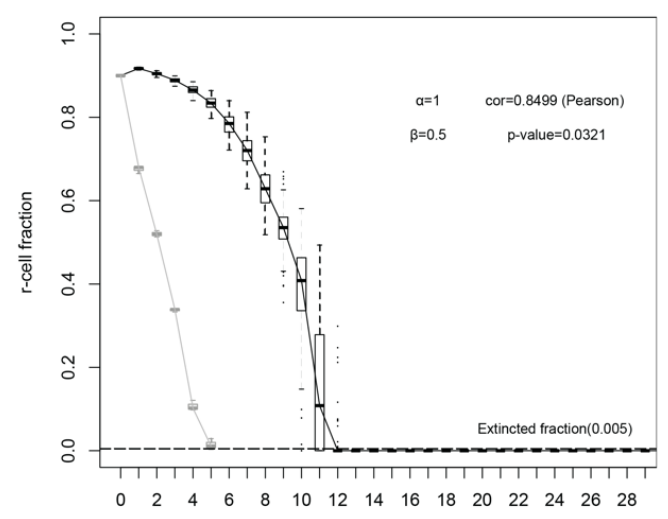

e

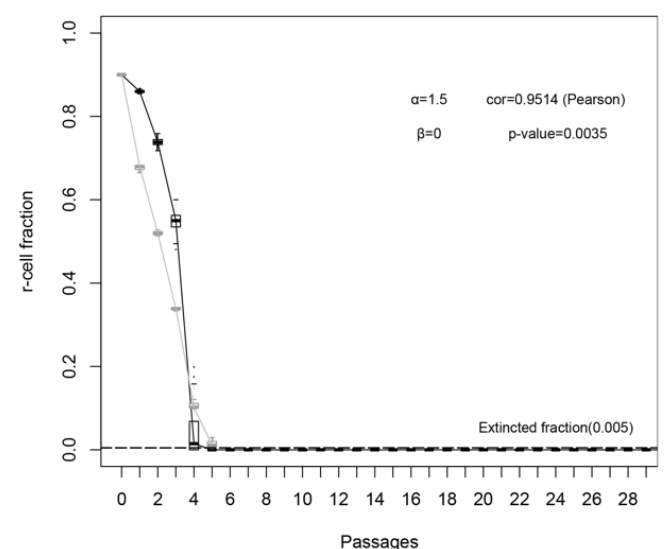

b
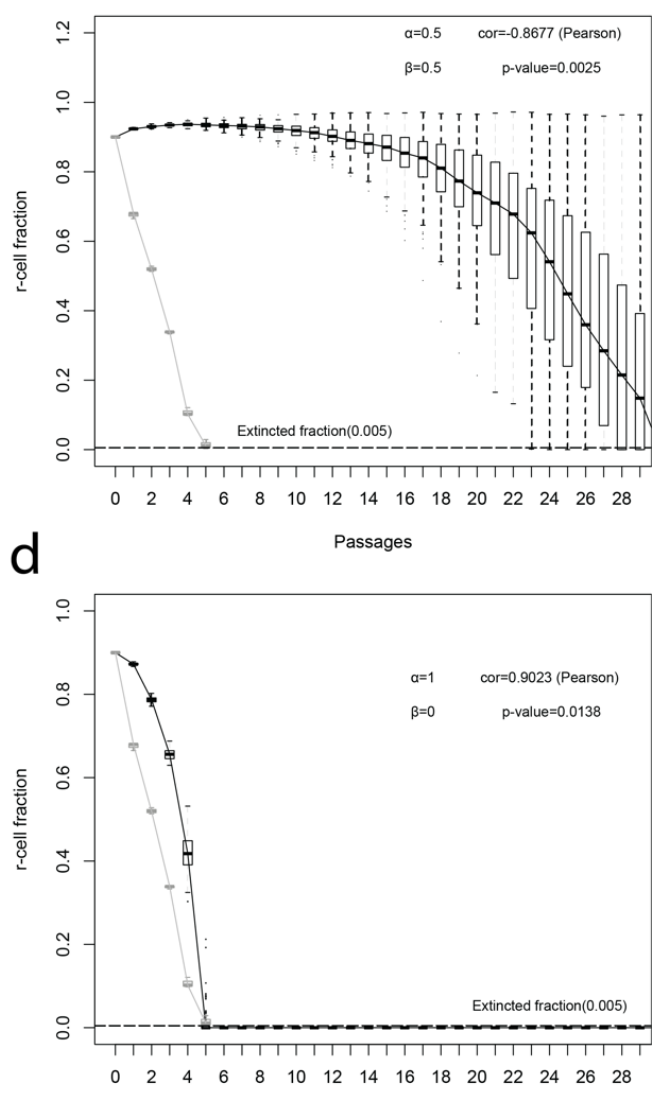

$f$

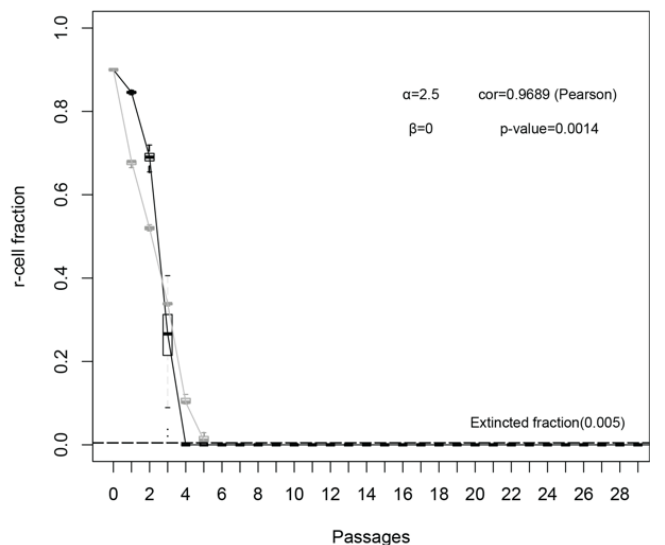

1003 Extended Data Figure 5 | Predicted dynamics of $\mathbf{r}$ - and K-cell mixed populations. The

1004 proportion of each type of cells in the population was measured when subculturing. Sub-

1005 figures show the predicted population dynamics with different $\alpha$ and $\beta$. Black boxes and lines 1006 represent simulation results. Gray boxed and lines represent observations. $n=100$ stochastic 1007 simulations per population, $\mathrm{n}=3$ independent experiments per population, mean $\pm \mathrm{SD}$. 


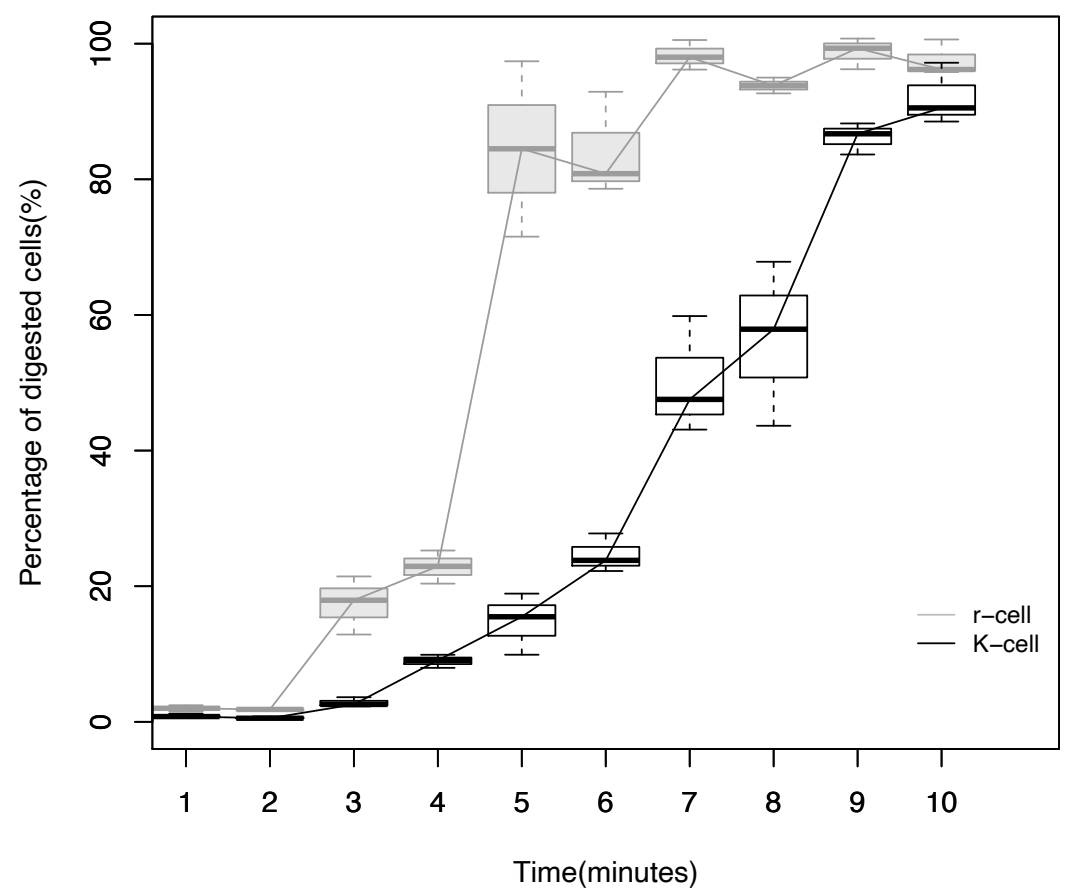

1010 Extended Data Figure 6 | Detachment curves of $\mathbf{r}$ - and K-cells under trypsinization.

1011 Cells were digested by $1 \mathrm{X}$ Trypsin under room temperature. Cells which detached under

1012 trypsinization were counted every minute. The $\mathrm{x}$-axis represents time and the $\mathrm{y}$-axis

1013 represents the proportion of total cells that have been digested. Grey lines and box diagrams

1014 represent observations of r-cell populations. Black lines and box diagrams represent

1015 observations of K-cell populations. $n=6$ independent experiments per population, mean \pm

1016 SD. This figure shows that it takes significantly longer to digest attached $\mathrm{K}$ than $\mathrm{r}$ cells. 


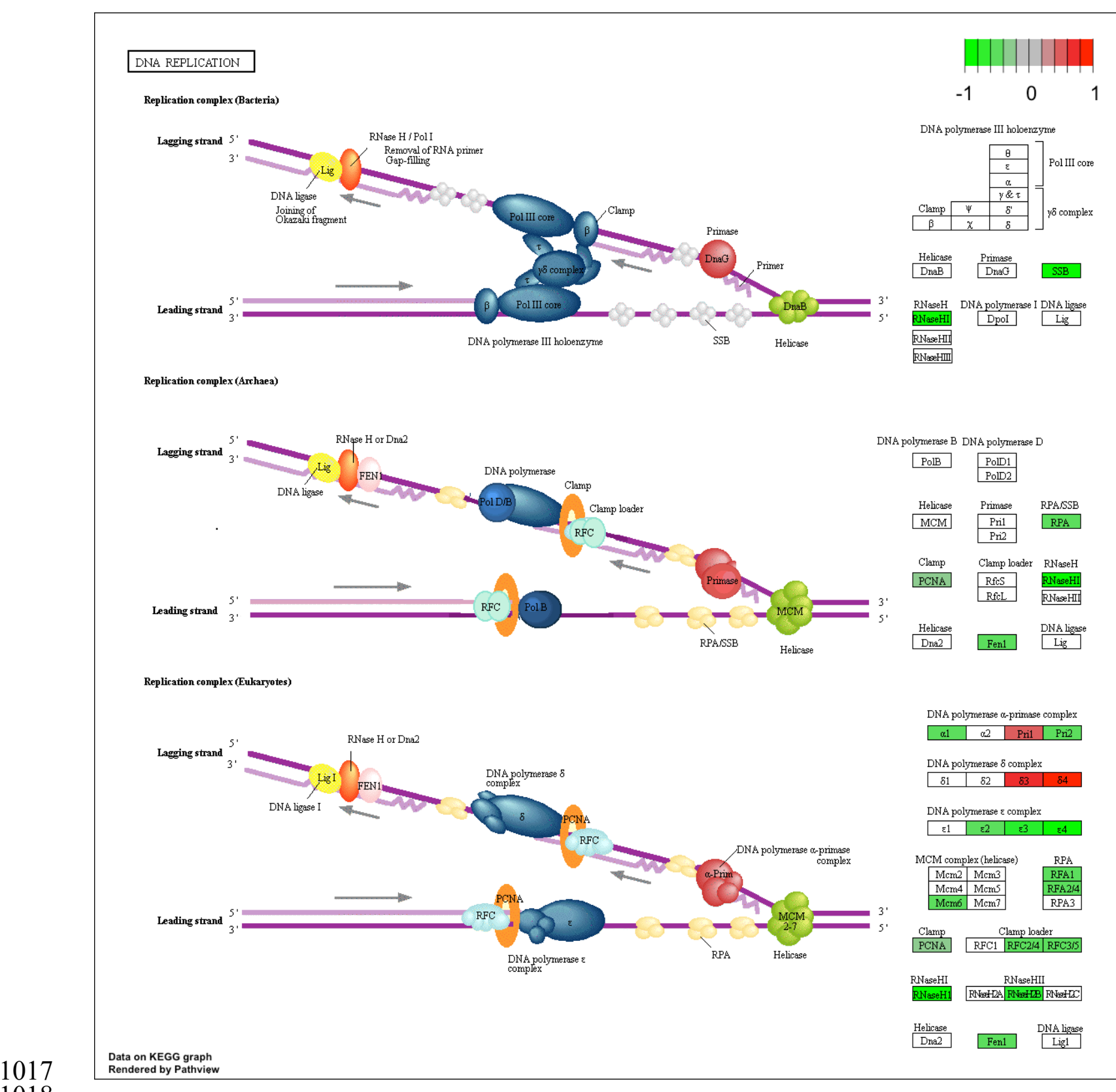

1018

1019

Extended Data Figure 7 | The DNA replication pathway is significantly lower expressed 1020 in $r$ cells under high than under low density. 


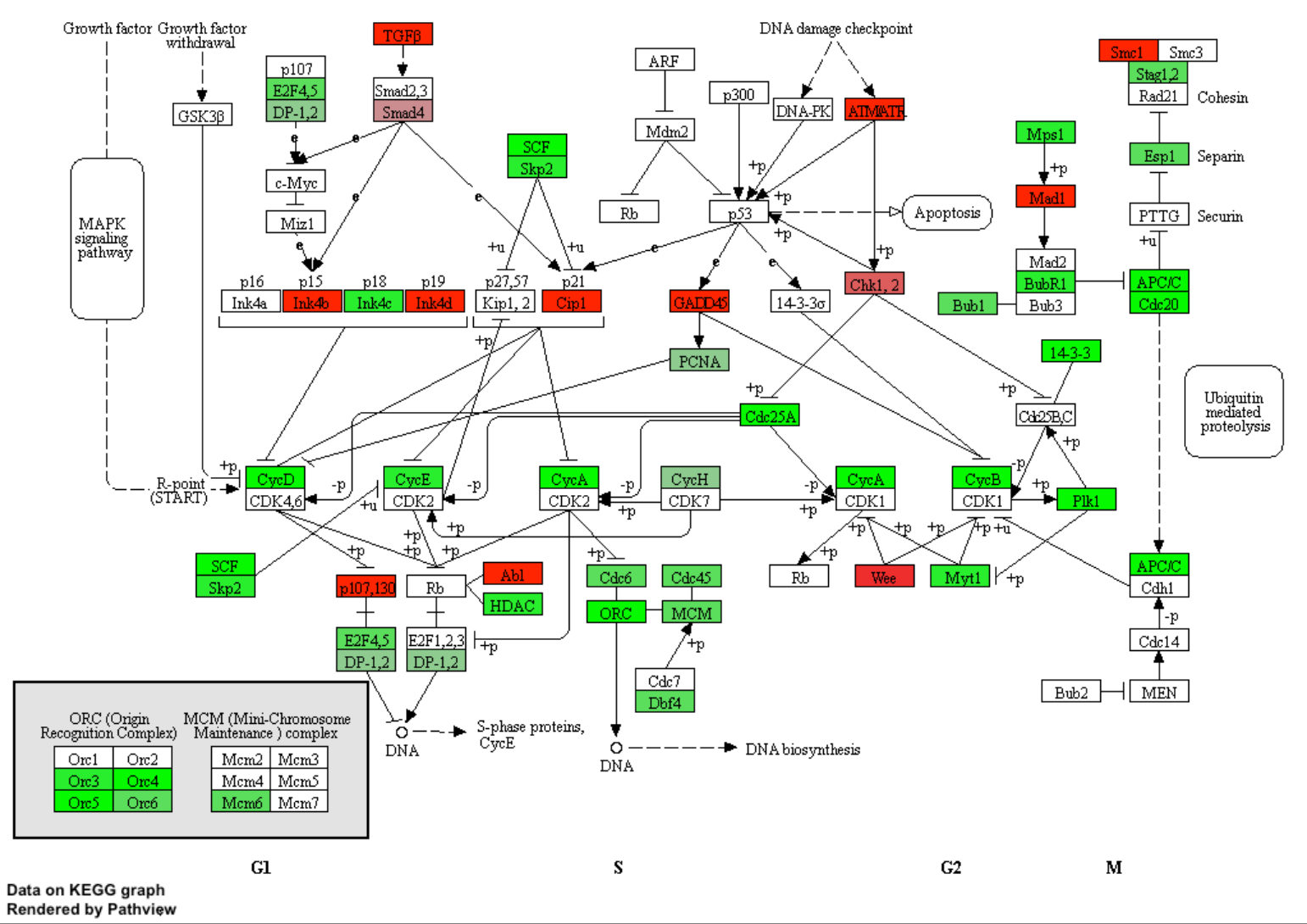
cells under high than under low density. 


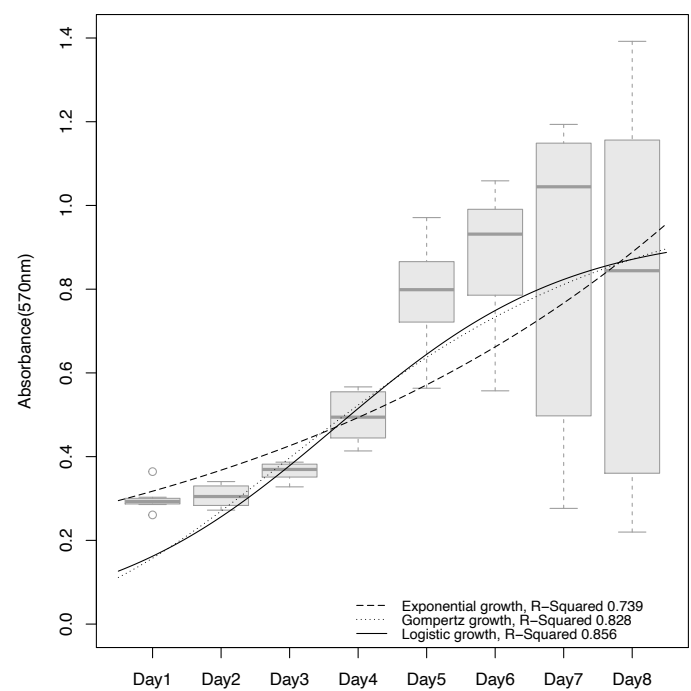

1026 Extended data Figure 9 | Growth model fitting. Cell growth was calculated using the MTT cell proliferation assay. We take the absorbance at $570 \mathrm{~nm}$ as the relative cell number. The assay was performed over eight days. We chose three population growth models: exponential, Gompertz, and logistic. Curves represent different models' predictions. 


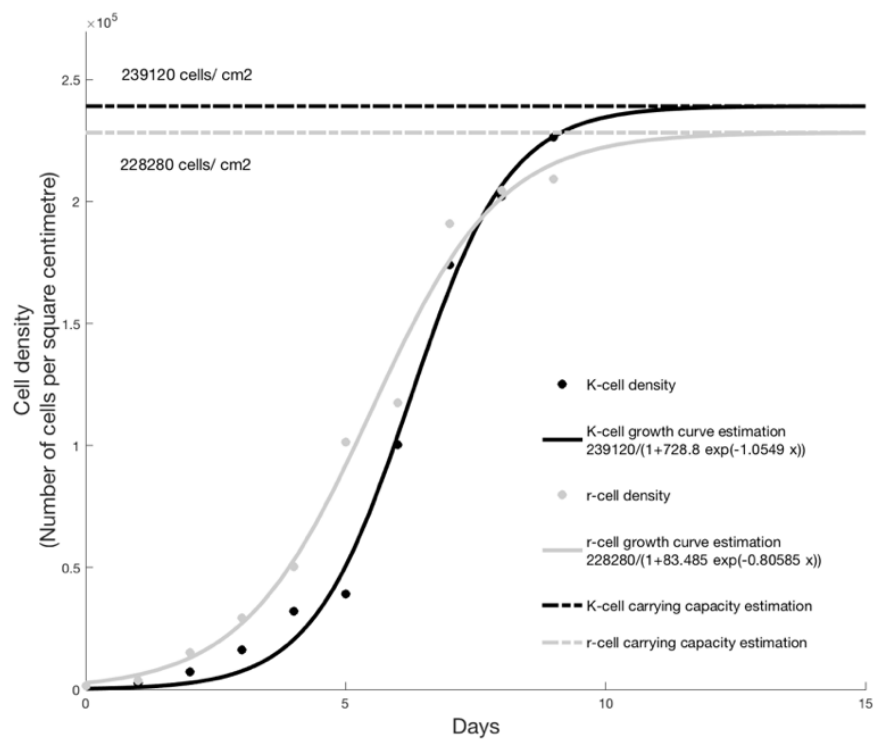

1030 Extended Data Figure 10 | Carrying capacity estimation. The X-axis represents days after cell seeding. The Y-axis represents cell density. The unit of cell density is the number of cells per square centimeter. Grey points represent the cell density of $\mathrm{r}$ - and black points of K cells. Data were collected from experiments. Solid grey and solid black lines represent estimated growth curves of $r$ - and K-cell populations respectively. Curve fitting was based on a logistic growth function. Parameters are shown in the legend. Adjusted $\mathrm{R}^{2}$ of the r-cell growth curve estimation is 0.985 , for K-cells it is 0.991 . The P-value of the r-cell growth curve is 239120 cells $/ \mathrm{cm}^{2}$ for $\mathrm{r}$ - and 228280 cells $/ \mathrm{cm}^{2}$ for $\mathrm{K}$ cells. 
a

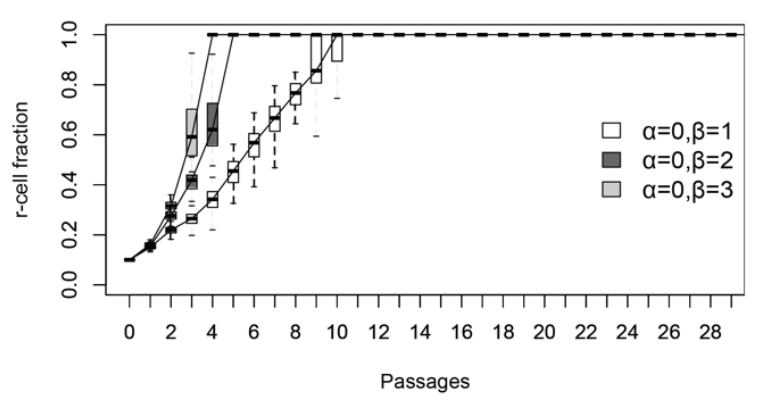

C

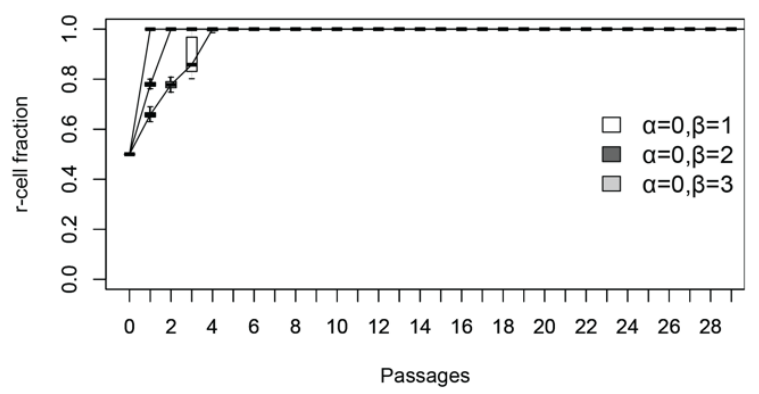

e

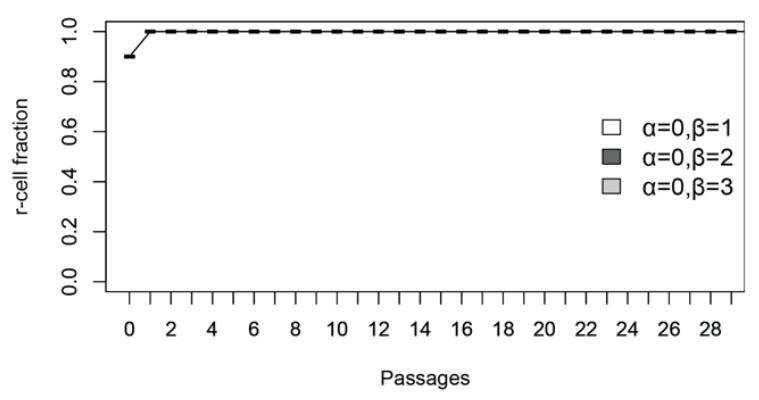

b

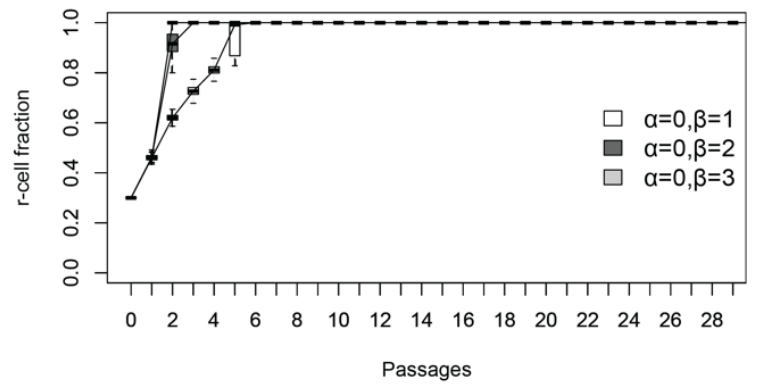

d

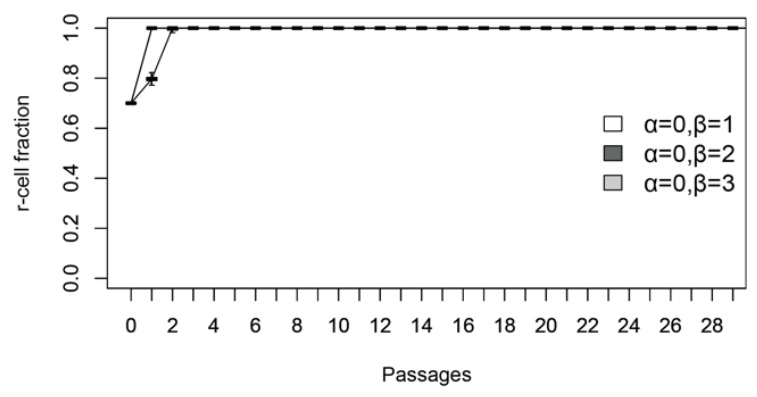

1040 Extended Data Figure $11 \mid$ Predicted dynamics of r-and K-cell mixted populations. The population growth model. The populations were initialed with cell density of

$10434 \times 10^{4}$ cells $/ \mathrm{cm}^{2}$ and subcultured every 72 hours. The proportion of $\mathrm{r}$ cells is a) $10 \%$, b) $30 \%$, c) $50 \%$, d) $70 \%$ e) $90 \%$ at the beginning. The proportion of each type of cells in a population was measured when subculturing. $\mathrm{n}=100$ stochastic simulations per population; mean $\pm \mathrm{SD}$. 

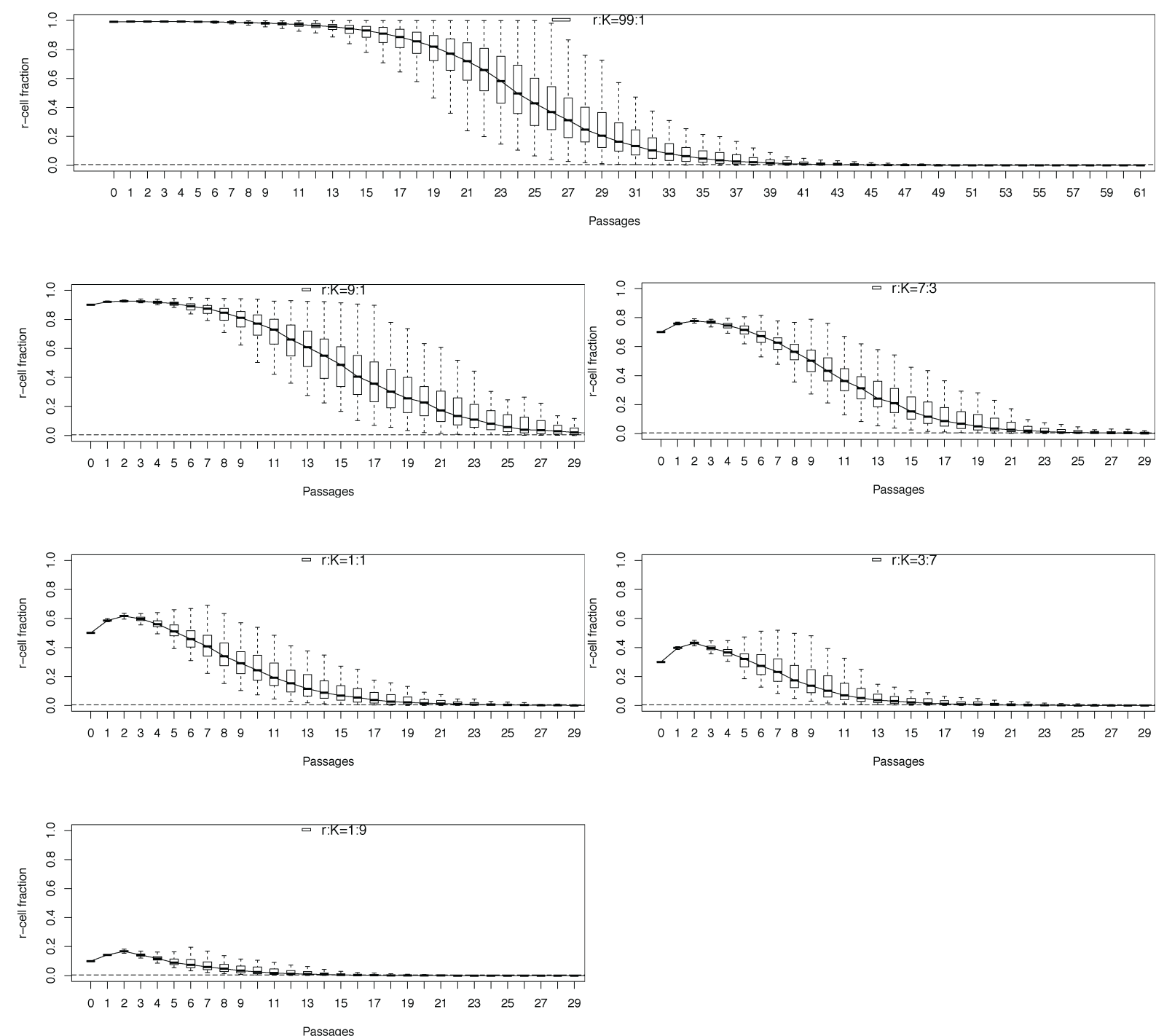

Extended Data Figure 12 | The dynamics of r- and K-cell mixture populations. Each panel shows 100 simulation predictions of a mixture population with a certain initial $\mathrm{r}$ and $\mathrm{K}$ cells ratio. The $\mathrm{x}$-axis represents the passage times and the $\mathrm{y}$-axis represents the $\mathrm{r}$-cell fraction. 

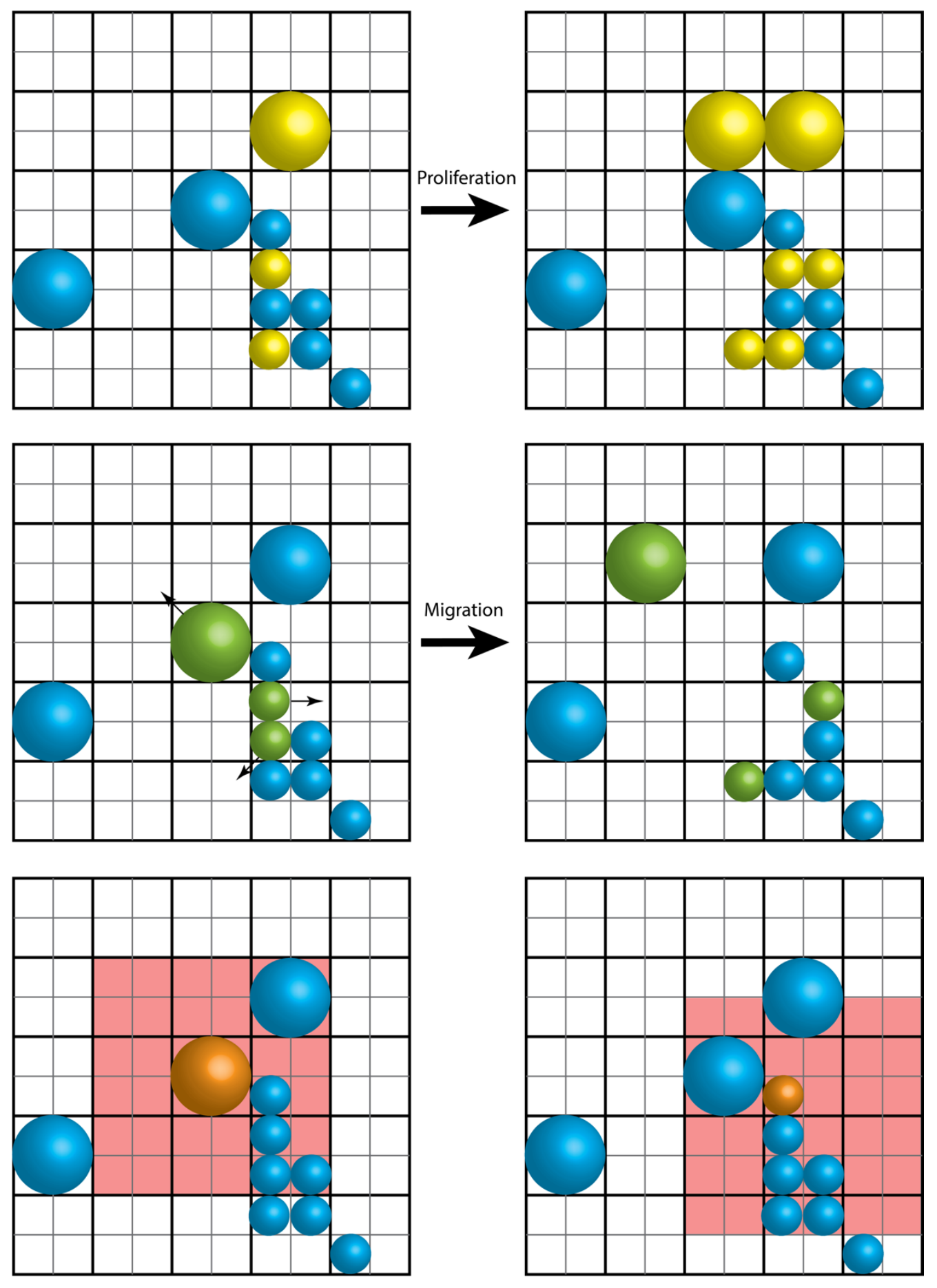

Density-dependent space (Big cell; 6*6 grids)

Density-dependent space (small cell; $6 * 6$ grids) cell growth space was assumed to be a two-dimensional planar grid. The location of cells is determined by grid coordinates. Cell migration and division are on the two-dimensional grid plane. The first line represents the division process. Yellow cells are undergoing mitosis. The second row represents migration with migrated cells in green. The red regions in the third row represent density dependent regions of migrated cells (orange). 


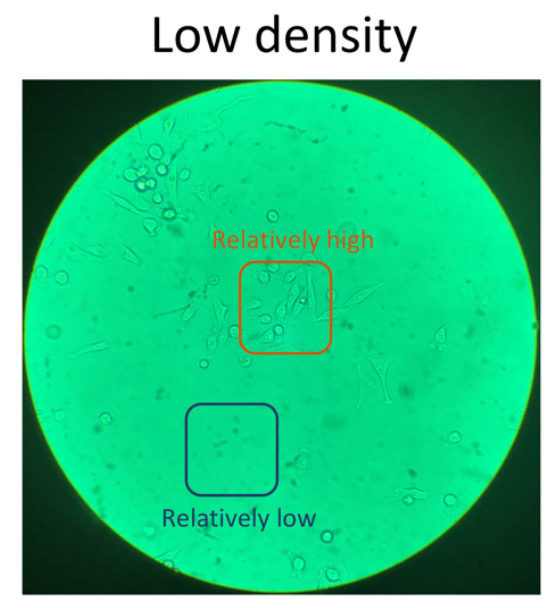

Low-density

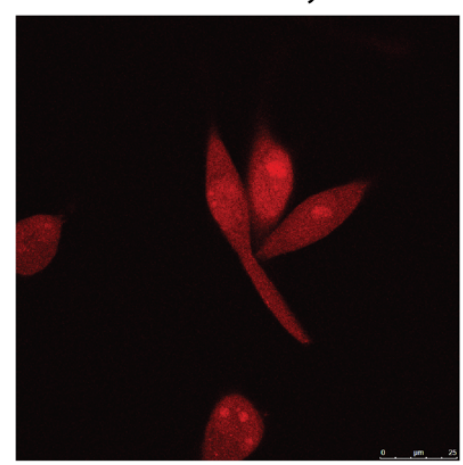

High density

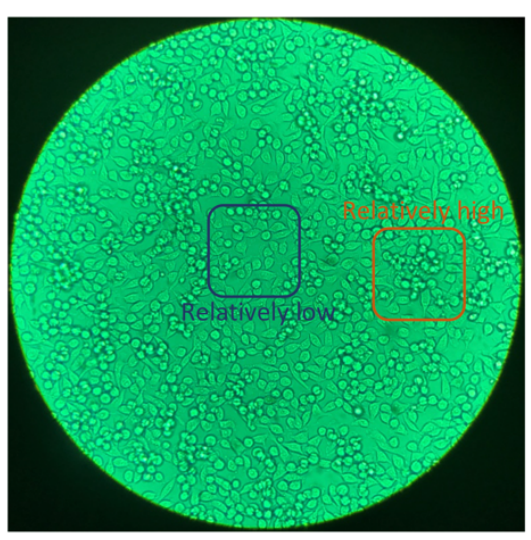

High-density

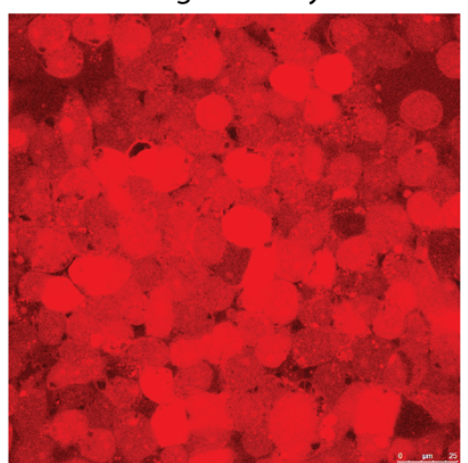

Extended Data Figure 14 | Density-dependent spatial heterogeneity and cell size

1063 Upper: Images show density-dependent spatial heterogeneity across culture densities: low 1064 density on the left and high density on the right.

1065 Bottom: Fluorescence imaging of cells at two densities. Red marks cell bodies. On the left is the image of cells growing under low density and on the right under high. 


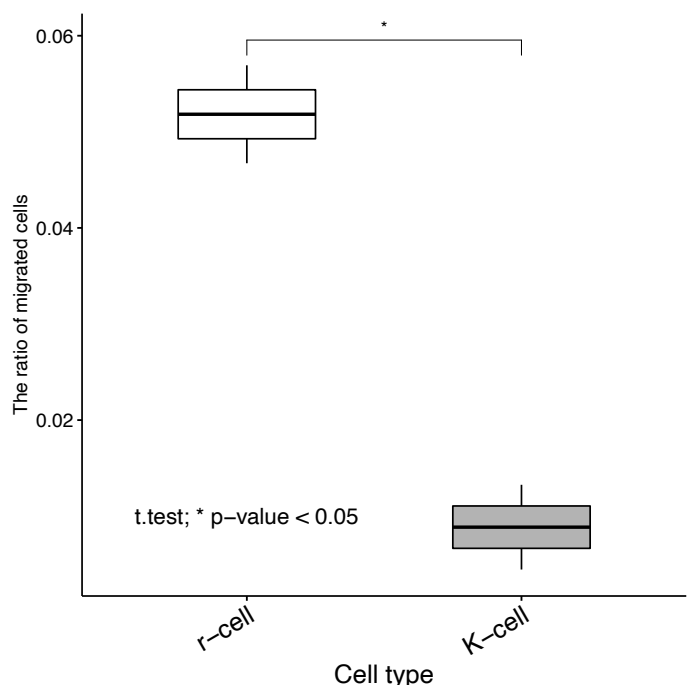

Extended Data Figure 15. Ratio of migrated cells. $r$ cells migrate more readily than $\mathrm{K}$ cells (t-test). The data were collected using a trans-well migration assay. $\mathrm{n}=6$ independent experiments; mean $\pm \mathrm{SD}$. 
bioRxiv preprint doi: https://doi.org/10.1101/829135; this version posted November 4, 2019. The copyright holder for this preprint (which

was not certified by peer review) is the author/funder. All rights reserved. No reuse allowed without permission.

1071 Extended Data Table 1 | The number of DEGs across comparisons.

1072

1073

1074

\begin{tabular}{cccc}
\hline Comparisons & $\begin{array}{c}\text { High-expressed } \\
\text { genes number }\end{array}$ & $\begin{array}{c}\text { Low-expressed } \\
\text { genes number }\end{array}$ & $\begin{array}{c}\text { Total DEGs } \\
\text { number }\end{array}$ \\
\hline KL vs. rL & 1748 & 1413 & 3161 \\
KH vs. KL & 1151 & 1126 & 2277 \\
rH vs. rL & 3284 & 3098 & 6382 \\
\hline
\end{tabular}

1075 
Extended Data Table 2 I Enrichment of DEGs in r- and K-cells under low-density.

\begin{tabular}{|c|c|c|c|}
\hline KEGG Pathway & Count & $\%$ & P-Value \\
\hline Spliceosome & 54 & 1.7 & $1.00 \mathrm{E}-10$ \\
\hline Pathways in cancer & 97 & 3.1 & $2.90 \mathrm{E}-05$ \\
\hline Ribosome biogenesis in eukaryotes & 30 & 1 & $9.70 \mathrm{E}-05$ \\
\hline Small cell lung cancer & 29 & 0.9 & $1.60 \mathrm{E}-04$ \\
\hline Hepatitis B & 40 & 1.3 & $1.10 \mathrm{E}-03$ \\
\hline PI3K-Akt signaling pathway & 79 & 2.5 & $2.00 \mathrm{E}-03$ \\
\hline ECM-receptor interaction & 26 & 0.8 & $3.20 \mathrm{E}-03$ \\
\hline RNA transport & 43 & 1.4 & $5.20 \mathrm{E}-03$ \\
\hline Proteasome & 15 & 0.5 & $9.50 \mathrm{E}-03$ \\
\hline Base excision repair & 12 & 0.4 & $1.40 \mathrm{E}-02$ \\
\hline p53 signaling pathway & 19 & 0.6 & $2.30 \mathrm{E}-02$ \\
\hline Amoebiasis & 27 & 0.9 & $2.30 \mathrm{E}-02$ \\
\hline Epstein-Barr virus infection & 43 & 1.4 & $2.80 \mathrm{E}-02$ \\
\hline Pyrimidine metabolism & 26 & 0.8 & $3.20 \mathrm{E}-02$ \\
\hline Hippo signaling pathway & 35 & 1.1 & $3.50 \mathrm{E}-02$ \\
\hline Axon guidance & 30 & 1 & $4.20 \mathrm{E}-02$ \\
\hline Cell cycle & 29 & 0.9 & $5.10 \mathrm{E}-02$ \\
\hline Arginine and proline metabolism & 14 & 0.4 & $6.10 \mathrm{E}-02$ \\
\hline Amyotrophic lateral sclerosis (ALS) & 14 & 0.4 & $6.10 \mathrm{E}-02$ \\
\hline Influenza A & 38 & 1.2 & $6.30 \mathrm{E}-02$ \\
\hline Pertussis & 19 & 0.6 & $6.30 \mathrm{E}-02$ \\
\hline AMPK signaling pathway & 28 & 0.9 & $6.70 \mathrm{E}-02$ \\
\hline Purine metabolism & 38 & 1.2 & $7.20 \mathrm{E}-02$ \\
\hline RNA degradation & 19 & 0.6 & $7.80 \mathrm{E}-02$ \\
\hline Complement and coagulation cascades & 17 & 0.5 & $9.90 \mathrm{E}-02$ \\
\hline
\end{tabular}


1078 Extended Data Table 3 | Top 25 pathways enriched in r- and K-cells under crowed culture.

\begin{tabular}{|c|c|c|c|c|}
\hline Term & Count & $\%$ & PValue & $\begin{array}{c}\text { Fold } \\
\text { Enrichment }\end{array}$ \\
\hline Proteasome & 19 & 1.07344633 & 9.32E-09 & 4.89157973 \\
\hline Spliceosome & 34 & 1.92090395 & $2.58 \mathrm{E}-08$ & 2.89584617 \\
\hline RNA transport & 34 & 1.92090395 & $1.30 \mathrm{E}-05$ & 2.23922989 \\
\hline Oxidative phosphorylation & 26 & 1.46892655 & $2.03 E-04$ & 2.2144706 \\
\hline Alzheimer's disease & 30 & 1.69491525 & $3.02 \mathrm{E}-04$ & 2.02283372 \\
\hline Ribosome biogenesis in eukaryotes & 19 & 1.07344633 & $4.70 \mathrm{E}-04$ & 2.47390239 \\
\hline Huntington's disease & 32 & 1.8079096 & $6.32 \mathrm{E}-04$ & 1.88797814 \\
\hline Parkinson's disease & 24 & 1.3559322 & 0.00293437 & 1.91456938 \\
\hline Non-alcoholic fatty liver disease (NAFLD) & 25 & 1.41242938 & 0.00310229 & 1.87547498 \\
\hline Epstein-Barr virus infection & 29 & 1.63841808 & 0.00448698 & 1.72899051 \\
\hline RNA polymerase & 9 & 0.50847458 & 0.00543855 & 3.18596311 \\
\hline mRNA surveillance pathway & 17 & 0.96045198 & 0.00545382 & 2.11619528 \\
\hline RNA degradation & 15 & 0.84745763 & 0.00669615 & 2.2067277 \\
\hline Ribosome & 22 & 1.24293785 & 0.00765604 & 1.83244937 \\
\hline Pyrimidine metabolism & 18 & 1.01694915 & 0.00895992 & 1.96059269 \\
\hline Lysosome & 19 & 1.07344633 & 0.01859407 & 1.77875627 \\
\hline Cytosolic DNA-sensing pathway & 12 & 0.6779661 & 0.02280654 & 2.12397541 \\
\hline Metabolic pathways & 128 & 7.23163842 & 0.02350298 & 1.18075506 \\
\hline Herpes simplex infection & 25 & 1.41242938 & 0.03073077 & 1.54752307 \\
\hline p53 signaling pathway & 12 & 0.6779661 & 0.03105377 & 2.02887203 \\
\hline Protein export & 6 & 0.33898305 & 0.04640999 & 2.95509622 \\
\hline Purine metabolism & 23 & 1.29943503 & 0.05854707 & 1.4803465 \\
\hline Protein processing in endoplasmic reticulum & 22 & 1.24293785 & 0.0668094 & 1.47463382 \\
\hline Lysine degradation & 9 & 0.50847458 & 0.08312794 & 1.96059269 \\
\hline Synaptic vesicle cycle & 10 & 0.56497175 & 0.09925729 & 1.79807442 \\
\hline
\end{tabular}


$1081 \quad$ Extended Data Table $4 \mid \boldsymbol{\alpha}$ and $\boldsymbol{\beta}$ estimation.

\begin{tabular}{|c|c|c|c||c|c|c|c|}
\hline $\boldsymbol{\alpha}$ & $\boldsymbol{\beta}$ & $\begin{array}{c}\text { Pearson } \\
\text { correlation } \\
\text { coefficient }\end{array}$ & P-value & $\boldsymbol{\alpha}$ & $\boldsymbol{\beta}$ & $\begin{array}{c}\text { Pearson } \\
\text { correlation } \\
\text { coefficient }\end{array}$ & P-value \\
\hline 2.5 & 0 & 0.9689388 & 0.00143221 & $\mathbf{2 . 2}$ & $\mathbf{0}$ & $\mathbf{0 . 9 7 2 2 5 5}$ & $\mathbf{0 . 0 0 1 1 4 4 4}$ \\
\hline 2 & 0 & 0.9676702 & 0.00155093 & 2.3 & 0 & 0.9707893 & 0.00126744 \\
\hline 1.5 & 0 & 0.9513884 & 0.00348719 & 2.4 & 0 & 0.9692185 & 0.00140667 \\
\hline 3 & 0 & 0.9389382 & 0.00547899 & 2.1 & 0 & 0.9681876 & 0.00150194 \\
\hline 0.5 & 0 & 0.9222155 & 0.00884034 & 2 & 0 & 0.9678161 & 0.00153704 \\
\hline 2 & 0.5 & 0.9203873 & 0.00925496 & 2.5 & 0 & 0.9666132 & 0.00165341 \\
\hline 1.5 & 0.5 & 0.9047305 & 0.01318207 & 1.9 & 0 & 0.966591 & 0.0016556 \\
\hline 1 & 0 & 0.9023298 & 0.01384333 & 2.6 & 0 & 0.9658321 & 0.00173122 \\
\hline 2.5 & 0.5 & 0.8532767 & 0.03071229 & 1.8 & 0 & 0.9641388 & 0.00190598 \\
\hline 1 & 0.5 & 0.8498899 & 0.03210835 & 2.7 & 0 & 0.9611661 & 0.00223283 \\
\hline 3 & 0.5 & 0.8459967 & 0.03374926 & 1.7 & 0 & 0.959654 & 0.00240886 \\
\hline 3 & 1 & 0.4874954 & 0.32668390 & 1.6 & 0 & 0.9552124 & 0.00296398 \\
\hline 0 & 0 & -0.2844327 & 0.58485660 & 2.8 & 0 & 0.953362 & 0.00321194 \\
\hline 0 & 1 & -0.6824631 & 0.13523590 & 1.5 & 0 & 0.9515176 & 0.00346884 \\
\hline 0 & 1.5 & -0.6824631 & 0.13523590 & 2.9 & 0 & 0.9476675 & 0.00403637 \\
\hline 0 & 2 & -0.6824631 & 0.13523590 & 3 & 0 & 0.9367681 & 0.005871 \\
\hline 0.5 & 1.5 & -0.6824631 & 0.13523590 & & & & \\
\hline
\end{tabular}

\begin{tabular}{|c|c|c|c|}
\hline 0.5 & 1.5 & -0.6824631 & 0.13523590 \\
\hline 0.5 & 2 & -0.6824631 & 0.13523590 \\
\hline 1 & 1.5 & -0.6824631 & 0.13523590 \\
\hline 1 & 2 & -0.6824631 & 0.13523590 \\
\hline 1.5 & 1.5 & -0.6824631 & 0.13523590 \\
\hline 1.5 & 2 & -0.6824631 & 0.13523590 \\
\hline 2 & 1.5 & -0.6824631 & 0.13523590 \\
\hline 2 & 2 & -0.6824631 & 0.13523590 \\
\hline 2.5 & 1.5 & -0.6824631 & 0.13523590 \\
\hline 2.5 & 2 & -0.6824631 & 0.13523590 \\
\hline 3 & 1.5 & -0.6824631 & 0.13523590 \\
\hline 3 & 2 & -0.6824631 & 0.13523590 \\
\hline 2.5 & 1 & -0.8229516 & 0.04424429 \\
\hline 0.5 & 0.5 & -0.8677189 & 0.02509009 \\
\hline 0 & 0.5 & -0.9578561 & 0.00262674 \\
\hline 2 & 1 & -0.9673633 & 0.00158035 \\
\hline 1.5 & 1 & -0.9828175 & 0.00044032 \\
\hline 1 & 1 & -0.9835389 & 0.00040422 \\
\hline 0.5 & 1 & -0.9973591 & 0.00001045 \\
\hline
\end{tabular}


$1083 \quad$ Extended Data Table 5 Single cell growth rate.

\begin{tabular}{|c|c|c|c|c|c|c|}
\hline \multicolumn{7}{|c|}{ Single cell growth rate } \\
\hline Samples & IN G & IN R & H1G3KS & H1R1KS & H1G3RS & H1R1RS \\
\hline 1 & 1.18205451 & 0.9099664 & 1.05785739 & 0.4169925 & 1.1529676 & 1.36096405 \\
\hline 2 & 0.78450625 & 1.09276245 & 0.96578718 & 0.3 & 0.63894989 & 1.20447356 \\
\hline 3 & 0.68331135 & 0.92571359 & 0.40356018 & 1.20420227 & 1.35024631 & 1.26211361 \\
\hline 4 & 0.96146344 & 0.37275673 & 0.96610808 & 0.75038257 & 1.26650438 & 1.29541963 \\
\hline 5 & 0.69223035 & 0.97243412 & 1.17496324 & 0.73516754 & 1.24553979 & 1.35627194 \\
\hline 6 & 0.55066724 & 0.96347845 & 0.10820526 & 1.06598844 & 1.29776714 & 1.27910611 \\
\hline 7 & 1.11262124 & 0.65023927 & 0.64227275 & 1.33353816 & 1.3162349 & 1.29989319 \\
\hline 8 & 0.78234633 & 0.32142857 & 0.62534911 & 0.0830075 & 1.34890222 & 1.22927817 \\
\hline 9 & 0.85056211 & 0.60949718 & 0.40645792 & 1.2428491 & 1.06745604 & 1.25850872 \\
\hline 10 & 0.97209214 & 0.78990066 & 0.89551763 & 1 & 1.19063932 & 1.31476819 \\
\hline 11 & 0.69328098 & 0.09441166 & 0.3050203 & 0.29657843 & 1.29025241 & 0.74968538 \\
\hline 12 & 0.28188874 & 0.9669731 & 1.22090362 & 0.1169925 & 1.35733656 & 1.27015772 \\
\hline 13 & 1.06924641 & 0.93169468 & 0.03571429 & 0.14150375 & 1.27256068 & 1.34576374 \\
\hline 14 & 0.83532878 & 0.86647011 & 0.59787896 & 0.53219281 & 1.00358289 & 1.32127623 \\
\hline 15 & 0.90082758 & 0.95006167 & 0.90651607 & 1.15065555 & 1.24181886 & 1.3181352 \\
\hline 16 & 1.12741936 & 1.16930541 & 0.38410313 & 1.09248125 & 1.34462084 & 1.38411497 \\
\hline 17 & 0.94026379 & 1.01658765 & 0.16374866 & 1.03257973 & 1.11478234 & 1.09955316 \\
\hline 18 & 1.22249553 & 1.03685187 & 1.13752093 & 0.99068906 & 1.24553253 & 1.51453513 \\
\hline 19 & 0.70769319 & 0.99006821 & 0.52363493 & 1.11065629 & 1.25292585 & 1.14394413 \\
\hline 20 & 0.3090178 & 0.57221968 & 0.69534322 & 0.95216004 & 1.20452535 & 0.80808175 \\
\hline 21 & 0.20838377 & 1.06415693 & 0.74422446 & 1.25041672 & 1.3004986 & 0.35686687 \\
\hline 22 & 1.04414208 & 0.71627403 & 0.10714286 & 1 & 1.20976265 & 1.34431378 \\
\hline 23 & 0.81863137 & 1.01558597 & 0.3187433 & 1.18371023 & 0.5992702 & 0.9137845 \\
\hline 24 & 0.77428678 & 0.69809307 & 0.98152095 & 0.79366379 & 1.19494849 & 1.38846475 \\
\hline 25 & 0.95431981 & 0.61747098 & 1.14700834 & 0.37598882 & 1.11092661 & 1.49837062 \\
\hline 26 & 1.06200509 & 1.05243698 & 1.04377307 & 0.1169925 & 0.11321161 & 1.45951409 \\
\hline 27 & 1.17748589 & 0.85243595 & 1.04125522 & 0.35108335 & 1.21091295 & 1.26717622 \\
\hline 28 & 1.02449193 & 0.9846867 & 0.35633143 & 0.54431378 & 1.23501737 & 1.43353816 \\
\hline 29 & 0.70446769 & 0.82035446 & 0.56899428 & 0.19967234 & 1.23319832 & 0.45395466 \\
\hline 30 & 0.65930187 & 0.68832903 & 1.04866898 & 0.99772799 & 1.32590857 & 0.2 \\
\hline 31 & 0.8158403 & 0.55060698 & 0.33996806 & 0.15849625 & 0.8263962 & 0.62407913 \\
\hline 32 & 0.92821544 & 1.03767951 & 1.20698559 & 0.5 & 0.11595502 & 1.50891297 \\
\hline 33 & 0.90263343 & 0.95049219 & 0.89434196 & 0.2299685 & 1.23633227 & 0.62419087 \\
\hline 34 & 0.74990959 & 0.40670889 & 0.46312742 & 0.9194603 & 1.07652077 & 1.37139771 \\
\hline 35 & 1.30573712 & 0.86764158 & 0.98416201 & 0.1169925 & 1.29667389 & 1.21301415 \\
\hline 36 & 0.57407648 & 1.00402174 & 0.77471437 & 1.19858419 & 0.97046398 & 1.39163564 \\
\hline 37 & 0.69373464 & 1.08973541 & 1.26907276 & 1.06438562 & 1.30892878 & 1.42041182 \\
\hline 38 & 0.86274954 & 0.57086811 & 0.37654 & 1.23151496 & 1.30859543 & 1.28812369 \\
\hline 39 & 1.11052423 & 0.19070893 & 0.80118862 & 1.1019417 & 1.11123277 & 1.30429845 \\
\hline 40 & 1.16363931 & 0.68239273 & 0.73597283 & 0.59188632 & 1.34714326 & 1.24576374 \\
\hline 41 & 0.31025775 & 0.70440812 & 1.17714937 & 1.09858419 & 1.30414223 & 1.06800298 \\
\hline 42 & 1.09899887 & 1.03028933 & 0.93832419 & 0.9509775 & 0.83086675 & 1.30887882 \\
\hline 43 & 1.02120064 & 0.77007585 & 0.9203289 & 0.40808175 & 1.33986971 & 1.53174597 \\
\hline 44 & 1.06970496 & 0.75111087 & 0.87874437 & 0.2 & 0.31939515 & 1.49887069 \\
\hline 45 & 0.41965783 & 0.75696406 & 0.7838964 & 1.12753486 & 1.20365572 & 0.38846475 \\
\hline 46 & 0.68318868 & 1.00157957 & 0.94014636 & 0.5169925 & 1.30990997 & 1.42316337 \\
\hline 47 & 1.11510448 & 0.97776 & 0.51172694 & 0.75038257 & 1.18687715 & 1.21357093 \\
\hline
\end{tabular}




\begin{tabular}{|c|c|c|c|c|c|c|}
\hline 48 & 0.35658708 & 0.78473438 & 0.9950518 & 0.3 & 1.20095467 & 0.44576374 \\
\hline 49 & 0.5841186 & 0.96386567 & 0.32020658 & 0.26767629 & 1.34738565 & 1.2258566 \\
\hline 50 & 0.6865186 & 0.26844754 & 0.21428571 & 0.933985 & 0.94737447 & 0.67234 \\
\hline 51 & 0.99740186 & 0.23728058 & 0.02696027 & 0.8 & 1.14735149 & 0.9950518 \\
\hline 52 & 0.2343992 & 1.26351184 & 1.04299544 & 0.8 & 0.78302047 & 1.15481502 \\
\hline 53 & 0.16042332 & 0.78684039 & 1.11587849 & 0.99083926 & 1.12030475 & 0.34330054 \\
\hline 54 & 0.81002746 & 0.60953941 & 0.21428571 & 0.81032878 & 0.2947848 & ---- \\
\hline 55 & 0.28893487 & 1.07336619 & 0.14285714 & 0.90947375 & ---- & ---- \\
\hline 56 & $\begin{array}{ll}--- \\
\end{array}$ & 0.99543854 & 0.95528537 & 0.96232719 & $\begin{array}{ll}--- \\
\end{array}$ & $\begin{array}{ll}--- \\
\end{array}$ \\
\hline 57 & $\begin{array}{ll}--- \\
\end{array}$ & 0.81517588 & 0.10714286 & 0.3 & $\begin{array}{ll}--- \\
--\end{array}$ & $\begin{array}{ll}--- \\
\end{array}$ \\
\hline 58 & ---- & 1.26762588 & 0.92306393 & 1.06219946 & ---- & ---- \\
\hline 59 & ---- & 0.60449721 & 0.94750032 & 0.88137812 & ---- & ---- \\
\hline 60 & ---- & 0.9382225 & 0.19946295 & 1.11357093 & ---- & ---- \\
\hline 61 & ---- & 0.68801814 & 0.19946295 & 0.96211361 & ---- & ---- \\
\hline 62 & ---- & 1.00723175 & 0.21428571 & 0.04150375 & ---- & ---- \\
\hline 63 & ---- & 0.73484628 & 0.33963482 & 1.26800298 & ---- & ---- \\
\hline 64 & ---- & 0.62672214 & 0.67506152 & 0.51083347 & ---- & ---- \\
\hline 65 & ---- & 0.82513271 & 0.36921685 & 0.05849625 & ---- & ---- \\
\hline 66 & ---- & 0.85640135 & ---- & 0.0509775 & ---- & ---- \\
\hline 67 & ---- & 0.94903135 & ---- & 0.2 & ---- & ---- \\
\hline 68 & ---- & 0.78134801 & ---- & 0.12288187 & ---- & ---- \\
\hline 69 & ---- & 0.09838884 & ---- & 0.82288187 & $\begin{array}{ll}--- \\
\end{array}$ & $\begin{array}{ll}--- \\
\end{array}$ \\
\hline 70 & ---- & 0.80426275 & ---- & 0.76617781 & ---- & ---- \\
\hline 71 & ---- & 0.26280965 & ---- & 0.3 & ---- & ---- \\
\hline 72 & ---- & ---- & ---- & 0.69858419 & ---- & ---- \\
\hline 73 & ---- & ---- & $\begin{array}{l}--- \\
\end{array}$ & 0.56438562 & ---- & ---- \\
\hline 74 & ---- & ---- & $\begin{array}{ll}--- \\
--\end{array}$ & 0.51083347 & ---- & ---- \\
\hline 75 & ---- & ---- & ---- & 0.69645165 & ---- & ---- \\
\hline 76 & ---- & ---- & $\begin{array}{ll}--- \\
--\end{array}$ & 0.39138389 & $\begin{array}{ll}--- \\
--\end{array}$ & $\begin{array}{ll}--- \\
--\end{array}$ \\
\hline
\end{tabular}

